\title{
High-resolution measurements from the airborne Atmospheric Nitrogen Dioxide Imager (ANDI)
}

\author{
J. P. Lawrence ${ }^{1, \text { a }}$, J. S. Anand ${ }^{1}$, J. D. Vande Hey ${ }^{1}$, J. White ${ }^{1}$, R. R. Leigh ${ }^{1}$, P. S. Monks ${ }^{2}$, and R. J. Leigh ${ }^{1}$ \\ ${ }^{1}$ EOS Group, Department of Physics and Astronomy, University of Leicester, Leicester, LE1 7RH, UK \\ ${ }^{2}$ Department of Chemistry, University of Leicester, Leicester, LE1 7RH, UK \\ ${ }^{a}$ now at: Geospatial Insight Ltd, Coleshill, B46 3AD, UK \\ Correspondence to: R. J. Leigh (rl40@le.ac.uk)
}

Received: 1 April 2015 - Published in Atmos. Meas. Tech. Discuss.: 5 June 2015

Revised: 9 October 2015 - Accepted: 29 October 2015 - Published: 10 November 2015

\begin{abstract}
Nitrogen dioxide is both a primary pollutant with direct health effects and a key precursor of the secondary pollutant ozone. This paper reports on the development, characterisation and test flight of the Atmospheric Nitrogen Dioxide Imager (ANDI) remote sensing system. The ANDI system includes an imaging UV/Vis grating spectrometer able to capture scattered sunlight spectra for the determination of tropospheric nitrogen dioxide $\left(\mathrm{NO}_{2}\right)$ concentrations by way of DOAS slant column density and vertical column density measurements.

Results are shown for an ANDI test flight over Leicester City in the UK on a cloud-free winter day in February 2013. Retrieved $\mathrm{NO}_{2}$ columns gridded to a surface resolution of $80 \mathrm{~m} \times 20 \mathrm{~m}$ revealed hotspots in a series of locations around Leicester City, including road junctions, the train station, major car parks, areas of heavy industry, a nearby airport (East Midlands) and a power station (Ratcliffe-on-Soar). In the city centre the dominant source of $\mathrm{NO}_{2}$ emissions was identified as road traffic, contributing to a background concentration as well as producing localised hotspots. Quantitative analysis revealed a significant urban increment over the city centre which increased throughout the flight.
\end{abstract}

\section{Introduction}

Statistical and epidemiological studies have linked atmospheric pollution in urban environments to health problems in humans (Latza et al., 2008). Recent studies estimate that the economic impact of poor air quality in the UK is as high as EUR 28 billion $\mathrm{yr}^{-1}$ (HoCEAC, 2011). In Germany, this figure is even higher at EUR 33 billion $\mathrm{yr}^{-1}$ due to industrial emissions alone (EEA, 2011). Nitrogen dioxide $\left(\mathrm{NO}_{2}\right)$ is an atmospheric pollutant abundant in urban areas owing to emissions from traffic exhaust, central heating systems and industrial activities. Correlations have been found between the atmospheric concentration of $\mathrm{NO}_{2}$ and respiratory symptoms, cardiovascular symptoms and hospital admissions (COMEAP, 2011). $\mathrm{NO}_{2}$ is also a known tracer/marker for other combustion products such as sub-micron particulate matter (Wehner and Wiedensohler, 2003) and is a precursor for ozone formation (Monks et al., 2009).

Road transport is the largest contributor to urban $\mathrm{NO}_{2}$ concentrations, and reductions of $\mathrm{NO}_{2}$ (and $\mathrm{NO}$ ) over the last 2 decades have not been as large as anticipated with $\mathrm{NO}_{2}$ levels being measured above legal limits at over $40 \%$ of European roadside air monitoring stations in 2010 (Carslaw et al., 2011). In the city of Leicester (UK), the focus region, approximately $90 \%$ of the atmospheric $\mathrm{NO}_{2}$ is emitted by traffic, of which approximately $60 \%$ is emitted by heavy goods vehicles and public transport, and like many cities in the UK Leicester is not meeting its European Commission regulatory limits on $\mathrm{NO}_{2}$ concentrations (Davies, 2011).

Understanding the concentration of $\mathrm{NO}_{2}$ in the urban atmosphere and its spatial distribution is high on many national agendas with the aim of minimising human exposure. Presently atmospheric $\mathrm{NO}_{2}$ concentrations at street level are determined from sparse in situ monitors which are often fed into dispersion models to provide estimates for its spatial distribution. However, relying on dispersion modelling introduces significant uncertainty to the $\mathrm{NO}_{2}$ concentration estimates between measurement sites owing to the complex to- 
pography of the urban landscape and the atmospheric chemistry which occurs outside of the sensing volumes of the in situ monitors (CERC, 2003; Vardoulakis et al., 2007).

To gain perspective on the distribution of $\mathrm{NO}_{2}$ around urban environments, a remote sensing instrument known as the Atmospheric Nitrogen Dioxide Imager (ANDI) was developed at the University of Leicester. The main component of the ANDI instrument is a compact imaging spectrometer known as CompAQS (Whyte et al., 2009), which was installed in a light aircraft alongside a series of ancillary systems and flown in a push-broom nadir configuration on the 28 February 2013. When flown at $900 \mathrm{~m}$ altitude the ANDI system produces maps of $\mathrm{NO}_{2}$ differential slant column densities (dSCDs) beneath the aircraft across swaths approximately $600 \mathrm{~m}$ wide with an across-swath resolution of approximately $5 \mathrm{~m}$ (see Sect. 2). The dSCDs are retrieved using the well-established differential optical absorption spectroscopy (DOAS) technique (Platt and Stutz, 2008), which following post-processing involving a radiative transfer model to generate air mass factors (AMFs) converts them into vertical column densities (VCDs) in units of molecules $\mathrm{cm}^{-2}$. VCDs provide estimates for the $\mathrm{NO}_{2}$ concentrations in vertical atmospheric columns having compensated for both viewing and solar geometries.

Aircraft are commonly used for testing and demonstrating new instruments and retrieval techniques, particularly for flight demonstrators of satellite instruments. For atmospheric measurements of $\mathrm{NO}_{2}$ in particular, aircraft open opportunities for validation of atmospheric modelling activities and have previously been used for validating satellite retrievals during intercomparison campaigns (e.g. Bucsela et al., 2008).

Imaging DOAS instruments which measure spectra across the nadir field of view have been previously employed in several flight campaigns (e.g. Heue et al., 2008; Popp et al., 2012; Schönhardt et al., 2014; General et al., 2014). As in the case of many satellite imaging instruments these operate a push-broom viewing geometry, in which spectra from multiple nadir viewing angles across the flight track are imaged onto the same charge-coupled device (CCD), which allows for high-spatial-resolution two-dimensional images of atmospheric pollution over the flight duration to be produced. These instruments are capable of imaging anthropogenic $\mathrm{NO}_{2}$ distributions over heavily polluted regions, such as industrial point-source emissions over the Highveld plateau in South Africa (Heue et al., 2008) and pollution originating from traffic in Zurich (Popp et al., 2012).

This paper describes the ANDI system and its test flight which focused specifically on the mapping of an urban agglomerate at very high spatial resolution. It is shown that with an appropriate flight plan, data collected by ANDI can provide insight into both spatial and temporal urban $\mathrm{NO}_{2}$ dynamics in a single flight, highlighting variability which is hidden to lower-resolution satellite measurements and in situ monitors.

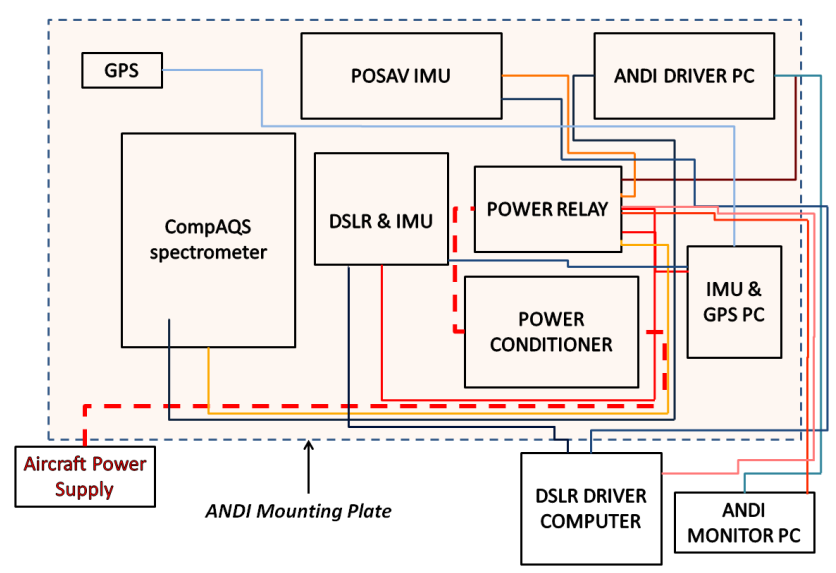

Figure 1. ANDI instrument schematic showing main components: the red lines represent power connections, and the blue lines represent communication connections.

\section{The ANDI system}

The ANDI system comprises of multiple subcomponents mounted on a rigid plate with two viewing apertures. The components include a CompAQS spectrometer (Whyte et al., 2009), the Global Positioning System (GPS), an inertial monitoring unit (IMU), a digital single-lens reflex (DSLR) camera and a power system to condition and convert the $28 \mathrm{~V}$ provided by the aircraft's generators into the 12 and $19 \mathrm{~V}$ used by the ANDI instruments. The ANDI system design is shown in Fig. 1.

\subsection{The CompAQS spectrometer}

The CompAQS spectrometer was originally built as a technology readiness improvement exercise towards the development of a compact grating spectrometer suitable for a small satellite mission (Whyte et al., 2009; Leigh et al., 2015). For application in the ANDI system the optical bench of CompAQS was modified and strengthened to allow for a vertical (nadir) configuration. In addition, the spectrometer's shutter mechanism was replaced with a CCD frame transfer system.

To minimise the transmission of vibration from the aircraft to the spectrometer and to protect the instrument from damage during landing, the spectrometer was mounted inside a secure metal frame using compressed foam as the fixing medium to prevent any hard contact between the spectrometer and the aircraft.

To mitigate the effect of electrical noise inherent in the production of power from the aircraft's generators a power conditioning unit was installed in the main circuit between the ANDI's power distribution hub and the aircraft's $28 \mathrm{~V}$ power supply (see Fig. 1).

Several changes have been made to the original CompAQS design in preparation for the flight. A different diffraction grating has been used to optimise the instrument for 
Table 1. Relevant specifications of the CompAQS spectrometer used in the ANDI system.

\begin{tabular}{ll}
\hline Component & Specification \\
\hline Spectral range & 420 to $590 \mathrm{~nm}$ \\
Spectral resolution & $1.5 \mathrm{~nm}$ \\
Field of view (azimuth) & $34^{\circ}$ \\
Angular resolution (across track) & $0.26^{\circ}$ \\
Detector type & $\mathrm{CCD}$ \\
Sensor size (post-frame transfer) & $512 \times 1024$ \\
Spectral binning & $2(512$ pixels $)$ \\
Spatial binning & $4(128$ pixels $)$ \\
\hline
\end{tabular}

$\mathrm{NO}_{2}$ retrieval. The original design had a UV optimised grating (2350 grooves $\mathrm{mm}^{-1}$ ), while in ANDI a grating of 1800 grooves $\mathrm{mm}^{-1}$ was used for the fitting window specified in Table 2. Additionally, in the Whyte et al. (2009) breadboard design a fold mirror was incorporated, which was removed in the ANDI iteration to simplify the design and to reduce internal stray light.

It is most likely that the degradation in the instrument line shape has occurred as a result of the build of the airborne version. Tolerances in the manufacture of the telescope mirrors, their mounts and the mounting on to the optical bench were not able to be compensated for; therefore the alignment of light incident on the entrance slit is not optimised.

The CompAQS spectrometer's across-track field of view (FOV) is curved owing to the use of a two-mirror Schwarzschild entrance optics configuration (Leigh et al., 2015). To provide an appropriate viewing geometry for data analysis purposes the spectrometer was mounted such that the curvature of its FOV pointed towards the aircraft's direction of travel. The instrument's FOV is approximately $34^{\circ}$ spread over 128 pixels $(600 \mathrm{~m}$ on the ground at $900 \mathrm{~m}$ altitude). The aircraft travelled with an average velocity of 155 knots $\left(80 \mathrm{~m} \mathrm{~s}^{-1}\right)$, resulting in a forward spatial resolution of approximately $80 \mathrm{~m}$.

The along-track spatial resolution of the CompAQS spectrometer is restricted by the maximum capture rate of the CompAQS CCD and its associated electronics. The capture rate during the test flight was approximately $1 \mathrm{~Hz}$. This rate is defined as the total time between subsequent measurements; once the CCD has been exposed for a single frame $(300 \mathrm{~ms})$, charge is transferred to the covered storage areas. When this happens, the vertical clocks are stopped on the exposed portion of the CCD, and the data are processed $(\sim 650 \mathrm{~ms})$.

The CompAQS spectrometer measures spectra in the visible region of the electromagnetic spectrum which are converted into dSCD and VCD measurements of atmospheric $\mathrm{NO}_{2}$ using the well-established DOAS technique (see Sect. 3.4 and 3.6). The specifications for the CompAQS spectrometer in its airborne configuration are given in Table 1 and Sect. 3.4.

\subsection{Attitude sensors}

To relate the $\mathrm{NO}_{2}$ measurements provided by CompAQS to a location on the Earth's surface a GPS module was built based on a Parallax GPS chip, and software was written to extract the GPS sentences and convert them into longitude, latitude and altitude data with $1 \mathrm{~s}$ temporal resolution. In addition, an IMU was installed to provide banking data to compensate for changes in viewing geometry during the data analysis process. The IMU data were not used in the data analysis for the results presented in this paper owing to data corruption; therefore an alternative data source was derived to account for banking as described in Sect. 3.3.

\section{Test flight and data processing chain}

The ANDI system was installed and flown in a CessnaReims F406 aircraft on 28 February 2013 from 12:30 to 14:30 (GMT). The weather conditions were suitable for flying the instrument but were non-ideal. The visibility in the boundary layer was slightly limited due to haze, and because of the time of year the solar elevation angle was between 26 and $30^{\circ}$, resulting in a shallow light path for the slant column measurements which rendered them susceptible to air mass factor uncertainties and spatial artefacts.

A flight plan was produced prior to the flight for operation at an altitude of $900 \mathrm{~m}$ with the sortie split into four separate stages: a flight along the M1 motorway to investigate pollution from fast moving traffic, a flight over Ratcliffe-onSoar power station to observe stack emissions, a repeated flight along a main route through Leicester City to investigate the temporal evolution of $\mathrm{NO}_{2}$ and a regular grid over Leicester City centre to investigate the spatial distribution of $\mathrm{NO}_{2}$ over the city centre. The latter portion of the flight plan formed the longest component of the flight, requiring 13 transects over the city centre to capture an area approximately $5 \mathrm{~km} \times 10 \mathrm{~km}$.

During the flight the ANDI instrument was accompanied by two operators, one to monitor the spectra collected by the CompAQS spectrometer and one to monitor the DSLR and attitude data. All systems operated successfully throughout the flight except for a minor error with the spectrometer which occurred for approximately $46 \mathrm{~s}$ towards the end of the flight, leading to a gap in coverage over Ratcliffe-on-Soar power station.

Following the flight the data collected by the ANDI instrument were collated on a server where algorithms were run to provide appropriate formatting and temporal offsets to account for clock differences between computers. The temporal offsets applied provided a first estimate to achieve temporal coherence between the data sets; however, additional work to correctly synchronise the data sets was required (see Sect. 3.2). 


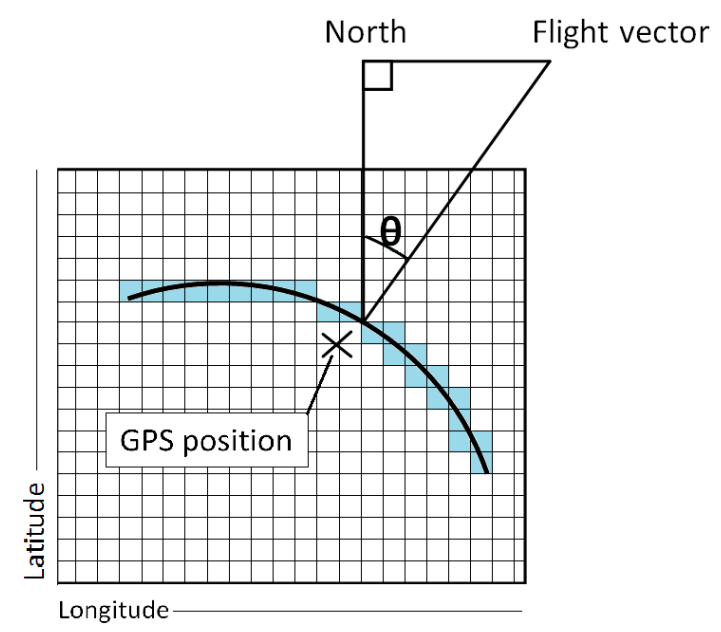

Figure 2. Schematic of the gridding process, showing the GPS location relative to the CompAQS field of view (curvature exaggerated for display purposes) shown as the black curve.

\subsection{Data gridding}

During the test flight, GPS provided longitude, latitude and altitude measurements at $1 \mathrm{~s}$ intervals. The first stage of the data gridding process involved allocating a GPS location to each measurement taken by the CompAQS spectrometer by running a nearest neighbour algorithm on their time stamps to synchronise the two data sets. The derivative of the GPS position data obtained from this process was then calculated to provide a direction of travel vector for the aircraft for each measurement throughout the flight.

Figures 2 and 3 present the geometry of the data gridding process and the variables which describe the orientation of the aircraft respectively. The relative position on the surface (in metres) of each pixel within the CompAQS FOV was assigned based on the altitude of the aircraft, its position and its direction of travel at the time of the measurement using the GPS location to represent the centre of the instrument's FOV (see Eqs. 1 to 6).

For consistency with the GPS data a non-regular spatial grid was defined in longitude/latitude coordinates with a spatial resolution of $20 \mathrm{~m}$ covering an area of $27 \times 50 \mathrm{~km}$. A search algorithm was used to fit each swath onto the grid, and any grid elements used more than once were averaged.

The calculation to determine the grid box locations for each surface pixel began with calculating the distance of each pixel from the centre of the instrument's FOV both in the across-track and the along-track directions. In the acrosstrack direction the distance $\left(d_{i k}\right)$ from the centre of the instrument's FOV is given as

$d_{i k}=a_{k} \tan \left(\phi_{i}+\psi_{k}\right)$,

where $i$ is the index associated with an across-track CompAQS pixel, $k$ is the index associated with each measurement swath, $a$ is the GPS-derived altitude of the aircraft, $\phi$ is

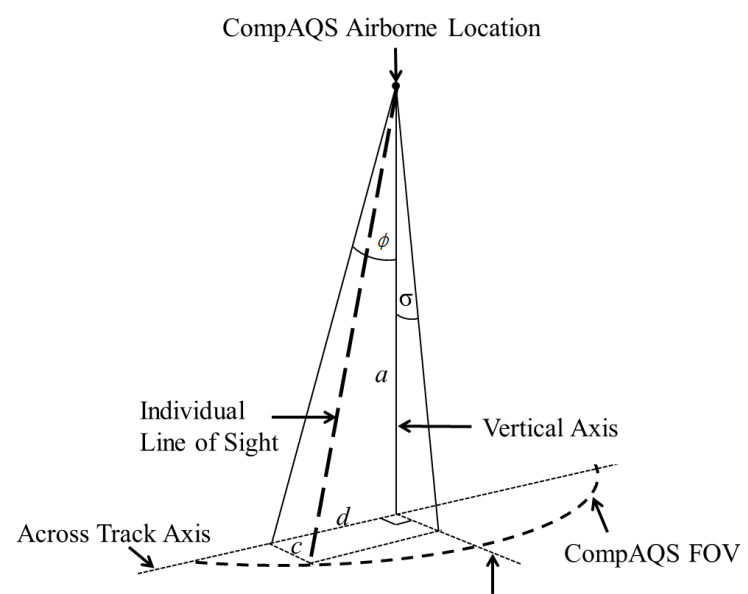

Along Track Axis

Figure 3. Schematic demonstrating the dimensions and geometry used to define the terms given in Eqs. (1) to (6).

the characterised CompAQS FOV angle for each pixel (see Fig. 3), and $\psi$ is the banking angle of the aircraft calculated from the GPS data (see Sect. 3.3). In the along-track direction the distance $c$ from the centre of the instrument's FOV is given as

$c_{i k}=a_{k} \tan \left(\sigma_{i}\right)$,

where $\sigma$ is the along-track angle of curvature of the CompAQS field of view for each pixel (see Fig. 3). In reality Eq. (2) would include an additional term to account for the pitch angle of the plane, but without reliable IMU data this could not be accounted for.

Using the results from Eqs. (1) and (2) the distance from the centre of the instrument's FOV in $x$ and $y$ coordinates is computed using

$x_{i k}=d_{i k} \sin \left(\theta_{k}\right)+c_{i k} \sin \left( \pm 90 \pm \theta_{k}\right)$,

$y_{i k}=d_{i k} \cos \left(\theta_{k}\right)+c_{i k} \cos \left( \pm 90 \pm \theta_{k}\right)$,

where $x$ and $y$ are the resultant pixel locations in metres from the centre of the instrument's FOV, and $\theta$ is the aircraft heading vector angle relative to north (see Fig. 2). Finally, using the results from Eqs. (3) and (4), the latitude and longitude coordinates of each pixel are computed using

lat $_{i k}=\left(x_{i k} / F_{k}^{\text {lat }}\right)+\operatorname{GPS}_{k}^{\text {lat }}$,

$\operatorname{long}_{i k}=\left(y_{i k} / F_{k}^{\text {long }}\right)+\operatorname{GPS}_{k}^{\text {long }}$,

where $F^{\text {long }}$ and $F^{\text {lat }}$ are the conversion factors between metres and longitude and latitude respectively, GPS ${ }^{\text {long }}$ and 


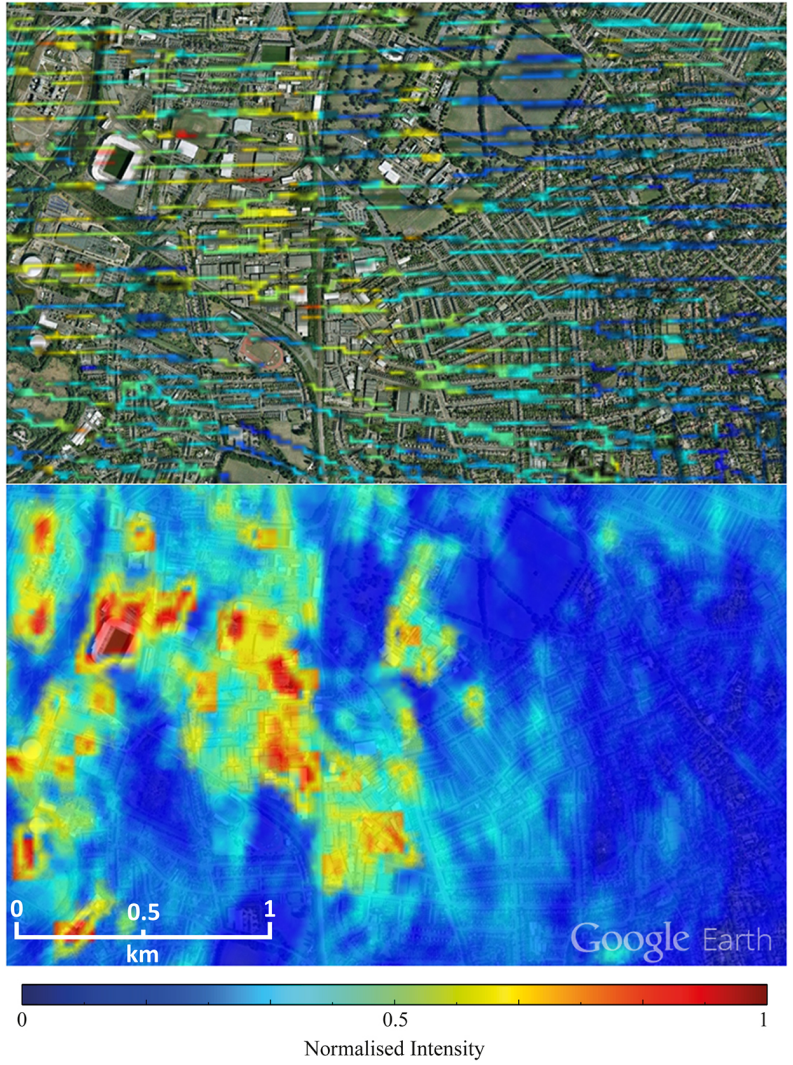

Figure 4. Google Earth overlays of the raw intensity $(442.7 \mathrm{~nm})$ with $20 \mathrm{~m}$ resolution with (bottom) and without (top) along-track linear interpolation and $2 \times 2$ grid cell smoothing. The pixel coordinates derived in Sect. 3.1 were assumed to be the centre of the gridded data in the top plot.

GPS $^{\text {lat }}$ are the GPS position coordinates of the aircraft for a given swath in longitude and latitude, and long and lat are the final longitude and latitude coordinates of each pixel in the CompAQS field of view which are fed to the gridding algorithm. Note the \pm signs in Eqs. (3) and (4) dictate that either $\mathrm{a}+$ or $\mathrm{a}-$ should be used depending on the angular quadrant of the heading vector $\theta$.

The $5 \mathrm{~m} \times 80 \mathrm{~m}$ spatial resolution of the CompAQS spectrometer resulted in significant gaps in the gridded data product at $20 \mathrm{~m}$ resolution. The pixel coordinates were also subject to the temporal accuracy of the GPS chip (1s) and so were approximations of their true location. To provide a spatially continuous data set, a linear interpolation algorithm was applied in the along-track direction of flight only, combined with a $2 \times 2$ grid box smoothing algorithm to aid in the identification of spatial features. Figure 4 presents an example of the effect of this process on the data, showing two data sets of raw intensity measurements from the test flight over the city centre at $442.7 \mathrm{~nm}$ before and after interpolation and smoothing. This smoothed data set is used in the analysis discussed later in this work.

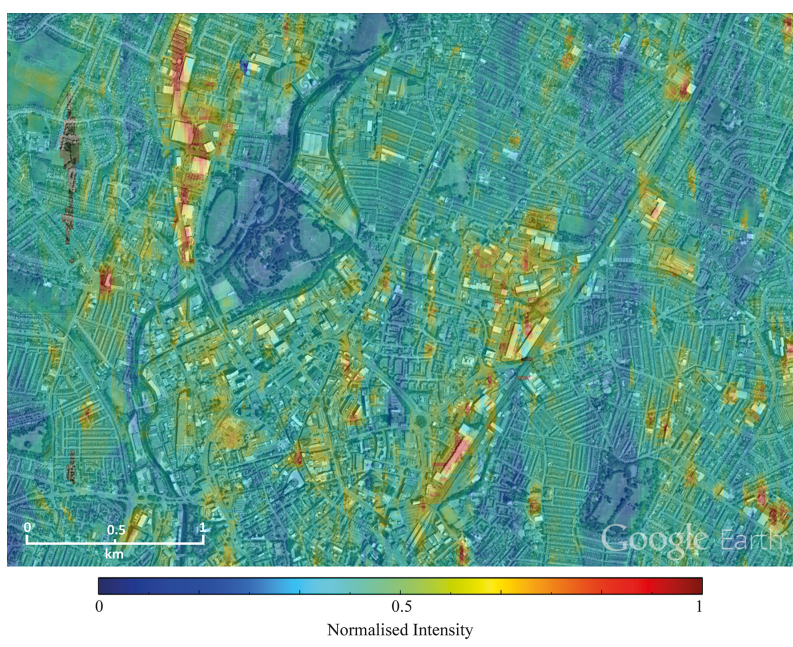

Figure 5. Google Earth overlay of the CompAQS $442.7 \mathrm{~nm}$ forward interpolated intensity data showing co-location of bright industrial units and high intensity data recorded by CompAQS.

To determine the possible impact of the unknown banking angle on this process the step change in GPS altitude per frame during the main phase of the flight (the Leicester City centre overpasses) was analysed to determine possible changes in the pitch angle. Neglecting the banking manoeuvres, it was found that the actual measurement location was $\pm 14 \mathrm{~m}$ away from the raw GPS position used in the gridding process. However, the frame rate of the CCD resulted in an average data gap of $90 \mathrm{~m}$. Therefore, the captured frame would have always been positioned within the tolerance of the along-track resolution of the interpolated data set.

\subsection{Data temporal synchronisation}

The temporal resolution of ANDI's GPS unit combined with the resolution of the CompAQS clock introduced an alongtrack spatial bias of approximately $160 \mathrm{~m}$ following initial temporal synchronisation. This uncertainty is sufficient to lead to potential spatial misinterpretation of data during the process of source attribution. To correctly georeference the $\mathrm{NO}_{2}$ retrievals, the interpolated intensity data from the CompAQS CCD at $442.7 \mathrm{~nm}$ were plotted and compared to features over Leicester City centre. Features which appeared significantly bright such as white industrial units were used as reference points to adjust the temporal synchronisation of the GPS and CompAQS data sets relative to one another until they were in good agreement. Figure 5 presents intensity measurements at $442.7 \mathrm{~nm}$ over the city centre to demonstrate the co-location of bright buildings with high-intensity measurements following a $160 \mathrm{~m}$ relative shift in the data sets. It should be noted that this correction was only performed on data taken during level flight, as during banking manoeuvres the roll angle would have lead to additional uncertainty without accurate IMU measurements. 


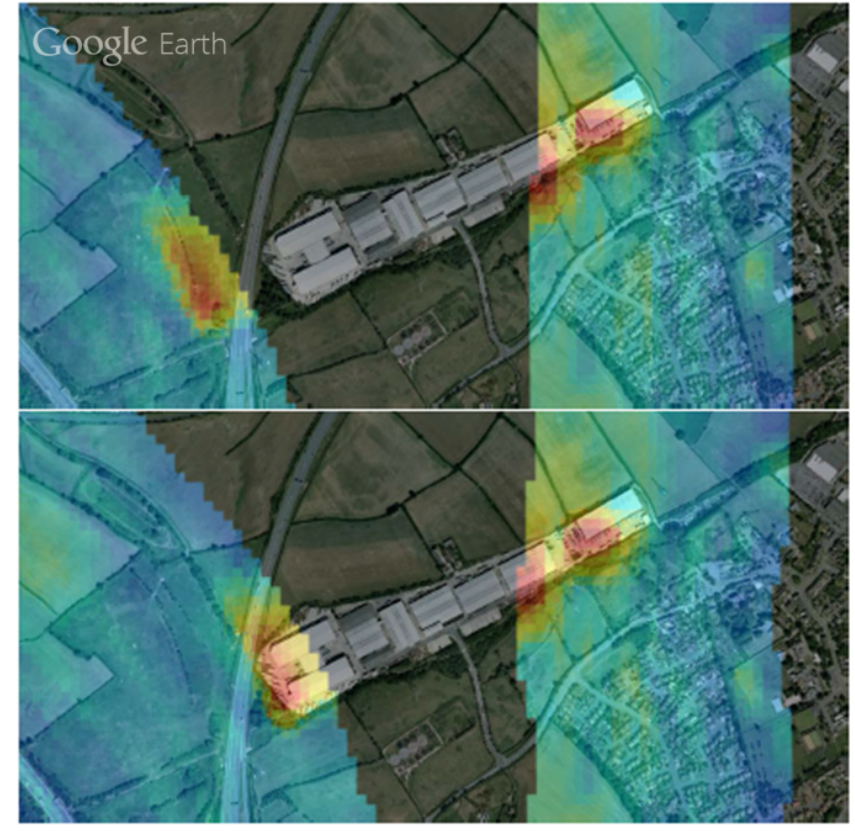

Figure 6. Top: CompAQS $442.7 \mathrm{~nm}$ intensity data showing incorrect georeferencing prior to banking correction. Bottom: CompAQS $442.7 \mathrm{~nm}$ intensity data showing improved georeferencing following banking correction. Two swaths are shown, one during banking (left) and one during level flight (right). Both swaths are overlaid on Google Earth.

\subsection{Aircraft attitude compensation}

Throughout the flight the aircraft's necessary banking during manoeuvres introduced a variable FOV for the CompAQS spectrometer. To compensate for banking in the gridding process a data set of banking angles as a function of flight time was generated. These data would have been provided by the onboard IMU had the data not been corrupted; instead it was calculated by taking the temporal derivative of the aircraft's bearing vector derived from the GPS data combined with a scaling factor. The magnitude of the scaling factor was determined empirically by comparing the raw intensity measurements at $442.7 \mathrm{~nm}$ against bright surface features (see Fig. 6). The banking angle approximation would in future need to be replaced by the use of IMU data as the approximation's accuracy cannot be guaranteed for all banking situations.

\section{$3.4 \mathrm{NO}_{2}$ retrieval}

The $\mathrm{NO}_{2}$ differential slant columns were derived using the DOAS technique in a fitting window from 432 to $493 \mathrm{~nm}$. The fitting window was selected to be reflective of similar studies, to permit fitting over a broad wavelength range and to minimise the fit RMS. A number of wavelength windows (approximately 20) were tested, with the final configuration selected, on the criteria above.
Table 2. Fitting parameters used for the DOAS fits in this work.

\begin{tabular}{|c|c|}
\hline Fitting parameter & Value \\
\hline Fitting window & $432-493 \mathrm{~nm}$ \\
\hline Reference & Row specific reference measured over \\
\hline Spectrum & remote farmland \\
\hline Line shape & $\begin{array}{l}\text { Gaussian (wavelength dependent, cal- } \\
\text { culated from QDOAS) }\end{array}$ \\
\hline Solar reference & Solar atlas (Kurucz et al., 1984) \\
\hline Wavelength & NLLS fit of object and reference spec- \\
\hline Calibration & trum to solar reference \\
\hline \multicolumn{2}{|l|}{ Cross sections } \\
\hline $\mathrm{NO}_{2}$ & $\begin{array}{l}\text { Vandaele et al. }(1996)\left(T=294 \mathrm{~K}, I_{0}\right. \\
\left.\text { correction: } 1.0 \times 10^{16} \mathrm{molec}^{-2}\right)\end{array}$ \\
\hline $\mathrm{O}_{3}$ & $\begin{array}{l}\text { Bogumil et al. }(2003)\left(T=223 \mathrm{~K}, I_{0}\right. \\
\left.\text { correction: } 1.0 \times 10^{20} \mathrm{molec} \mathrm{cm}^{-2}\right)\end{array}$ \\
\hline $\mathrm{O}_{4}$ & Greenblatt et al. (1990) \\
\hline Ring & $\begin{array}{l}\text { Modelled by QDOAS (Chance and } \\
\text { Spurr, 1997) }\end{array}$ \\
\hline $\mathrm{H}_{2} \mathrm{O}$ & Rothman et al. (2003) \\
\hline $\mathrm{CHOCHO}$ & Volkamer et al. (2005) \\
\hline Polynomial & Fourth order \\
\hline
\end{tabular}

The fitting routine was performed using the software QDOAS (Fayt et al., 2015). Included in the fit were cross sections for $\mathrm{NO}_{2}, \mathrm{O}_{3}, \mathrm{CHOCHO}, \mathrm{O}_{4}, \mathrm{H}_{2} \mathrm{O}$ and the Ring effect (Chance and Spurr, 1997), which were convolved with the wavelength-dependent Gaussian line shape calculated with the QDOAS software. These cross sections were also empirically corrected for the solar $I_{0}$ effect (Aliwell et al., 2002). A fourth-order polynomial was used to remove broadband structures, and no offset correction was applied. The fitting parameters are summarised in Table 2.

For this work no offset was fitted to account for spectral defects such as stray light. The removal of the offset within the DOAS fit did not substantially change the spatial structure in the VCD data but did marginally improve RMSderived error estimates. An increase of approximately $20 \%$ in the fitted $\mathrm{NO}_{2} \mathrm{dSCD}$ was observed. Future analysis should include a detailed examination of the impact of the offset fitting, particularly if extending analysis through to retrieval of surface volume mixing ratios.

Each across-track pixel was attributed an individual reference spectrum, wavelength calibration and wavelength dependent instrument line shape. The wavelength calibration was performed using six sub-windows from 428 to $496 \mathrm{~nm}$, with a single wavelength calibration used for each acrosstrack pixel, following determination of negligible wavelength registration variability during the flight. The wavelength calibration was based on adjusting the Fraunhofer lines of the spectra based on a reference solar atlas (Kurucz et al., 1984), using a non-linear least squares fit (Fayt et al., 2015). From 


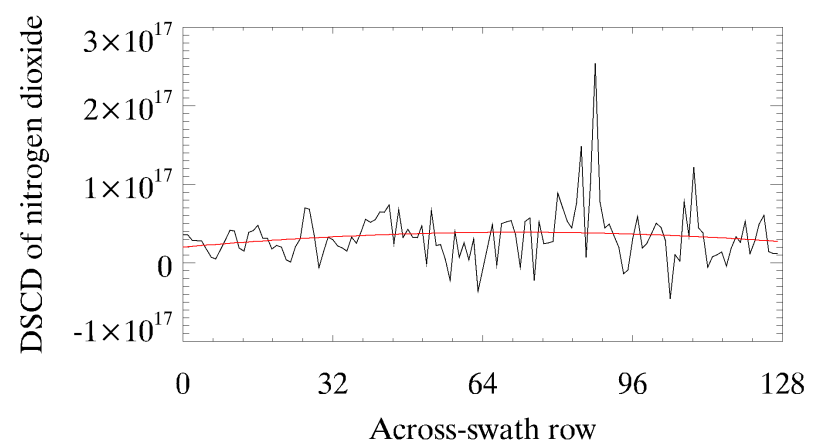

Figure 7. Destriping procedure on the data from the ANDI instrument. In black are mean dSCD measurements from each acrosstrack pixel, averaged over the entire flight. In red are mean dSCDs after destriping has been applied.

this, a wavelength-dependent shift and Gaussian line shape were calculated over the whole spectral window.

The reference spectra were measured at $12: 33: 56 \pm 2 \mathrm{~s}$ (GMT) over a region of farmland to the north of Leicester which was determined to have minimal influence from local emissions of $\mathrm{NO}_{2}$ and therefore could be considered a uniform measure of background $\mathrm{NO}_{2}$ for all across-track pixels. Errors on slant columns were calculated from the reduced chi-squared statistic of the DOAS fit (Fayt et al., 2015).

Data from the ANDI instrument exhibited striping on first analysis. This was likely caused by across-track defects in the $\mathrm{CCD}$, spatially varying $\mathrm{NO}_{2}$ within the reference region or differences in $\mathrm{NO}_{2}$ sensitivity across the swath owing to changing instrument line shape. A correction was applied to remove this striping using all measurements recorded over Leicester City and surrounding rural areas (4500 along-track pixels). Data over Ratcliffe-on-Soar power station and East Midlands Airport were excluded to avoid any influence of significant discrete plumes. For each across-track pixel, a mean dSCD over the flight was calculated and a second order polynomial fitted across all of these values. Outputs from this process are shown in Fig. 7.

Over the entire flight, deviation from this polynomial curve was interpreted as a bias in the measurement from the across-track pixel in question. Therefore a correction factor was applied to adjust the mean dSCD value for each acrosstrack pixel, so that the mean dSCD over the flight lay on this polynomial. The effectiveness of this process is demonstrated by the lack of striping in the final data set, despite significant inhomogeneity in $\mathrm{NO}_{2}$ measurements. Such processes can only be applied when sufficient measurements are taken to ensure that a smooth polynomial can be assumed for the whole data set, and no dominant $\mathrm{NO}_{2}$ sources are present in calculated means. The polynomial fitted includes AMF enhancements to the dSCDs towards the edges of the swath, and this structure is retained in order to ensure VCD calculations using AMF corrections can be correctly implemented.
Variability in throughput and gain for each across-track pixel was corrected to ensure that calculations of surface albedo could be implemented across the swath. This correction was calculated using data for the entire flight for the same wavelength used for the albedo calculations. A mean intensity for this pixel was calculated for the flight, and a correction factor applied to ensure that all across-track means were normalised.

\subsection{Air mass factor computation}

The dSCD measurements performed by the CompAQS spectrometer are the result of an integrated light path from the Sun to the ground pixel and then to the instrument. When the solar elevation angle is small (as it is in February in the UK) the dSCD measurements are difficult to interpret as a final data product owing to the shallow light path; therefore VCDs were derived by computing AMFs. AMFs account for enhancements in the light's atmospheric path length due to factors such as viewing geometry, aerosol scattering and surface albedo. Therefore, the VCD (Eq. 7) may be defined as the ratio of the SCD to the AMF (Solomon et al., 1987)

$\mathrm{VCD}=\frac{\mathrm{SCD}}{\mathrm{AMF}}$

To compute the effects of atmospheric scattering the atmosphere can be modelled as a set of altitude-resolved discrete layers. For optically thin species such as $\mathrm{NO}_{2}$ the AMF can be generalised as the linear sum of the contribution of each vertical layer to the total SCD divided by the total VCD (Palmer et al., 2001; Boersma et al., 2004):

$\mathrm{AMF}=\frac{\Sigma_{1} m_{1}(\hat{b}) x_{\mathrm{a}, 1}}{\Sigma_{1} x_{\mathrm{a}, 1}}$.

Here, $m_{1}$ is the box-AMF (BAMF), which represents the vertical sensitivity of layer $l$ to $\mathrm{NO}_{2}$. Computation of the BAMF is performed using a set of forward model parameters, summarised by the term $\hat{b}$. These parameters include the scene viewing geometry, surface albedo, $\mathrm{NO}_{2}$ profile and aerosol loading. Such parameters can either be derived from the instrument itself or determined from modelled data sets. An assumed a priori $\mathrm{NO}_{2}$ profile, $x_{\mathrm{a}}$, is partitioned to calculate the VCD for each layer, $x_{\mathrm{a}, 1}$. Computation of the BAMF requires the use of a radiative transfer model (RTM). Further discussion of the derivation of the AMF can be found in Rozanov and Rozanov (2010).

For this work the AMFs were calculated using the SCIATRAN RTM (v. 3.1.27, Rozanov et al., 2005). This model has previously been employed to compute AMFs for groundbased MAX-DOAS measurements (e.g. Kramer et al., 2008; Wang et al., 2012) as well as AMFs for satellite retrievals (e.g. Leitão et al., 2010; Hilboll et al., 2013). The observa- 


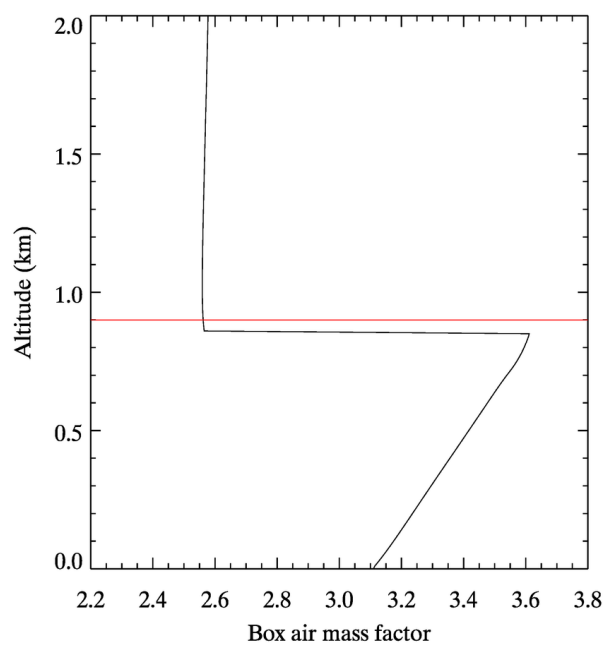

Figure 8. A typical box air mass factor calculated by the SCIATRAN RTM for a rural ground pixel. The red line indicates the instrument altitude $(0.9 \mathrm{~km})$ at the time of the measurement.

tional geometry was provided using the positional data described in Sect. 3.1, while considerations for other forward parameters are discussed herein. An example of the vertical BAMF profile produced by the RTM is shown in Fig. 8. The AMF is mostly sensitive to conditions below the flight altitude, as the $\mathrm{NO}_{2}$ and aerosol extinction profile chosen were at their largest below the boundary layer height.

A single $\mathrm{NO}_{2}$ profile used for the entire flight is shown in Fig. 9. The $\mathrm{NO}_{2}$ profile was taken from the spatial mean profile over Leicester at 12:00 (GMT) on the day of the flight as forecast by the MACC-II model ensemble (Stein et al., 2012) and was modelled using a mean surface height of $0.0948 \mathrm{~km}$. A high-resolution $(5 \mathrm{~m} \times 5 \mathrm{~m})$ digital elevation model (DEM) provided by BlueSky International Ltd. was used to correct for differences in local surface elevation assumed by MACC-II by scaling the profile to the DEM surface pressure using the technique explained in Zhou et al. (2009). The DEM data product provided by BlueSky International Ltd. did not include building topography. The effect of this on the retrieval is explored in the error analysis in Sect. 4.7.5.

A single aerosol scenario was assumed during the flight, the mixing state for which was defined using the World Meteorological Organization (WMO) database (Bolle, 1986), which assumes particle size distributions and spectral refractive indices for six components of atmospheric aerosol: water soluble, dust, oceanic, soot, stratospheric and volcanic. Table 3 presents a summary of the scenario used in the AMF computation.

By applying the aerosol backscatter gradient method similar to that described by de Haij et al. (2009) to data from a Campbell Scientific CS135 ceilometer located at 52.7814 (lat.), $-1.2844^{\circ}$ (long.), the boundary layer height during the flight was estimated at $0.7 \mathrm{~km}$, which has been reflected in the lowermost aerosol layer height in Table 3. For all scenar-

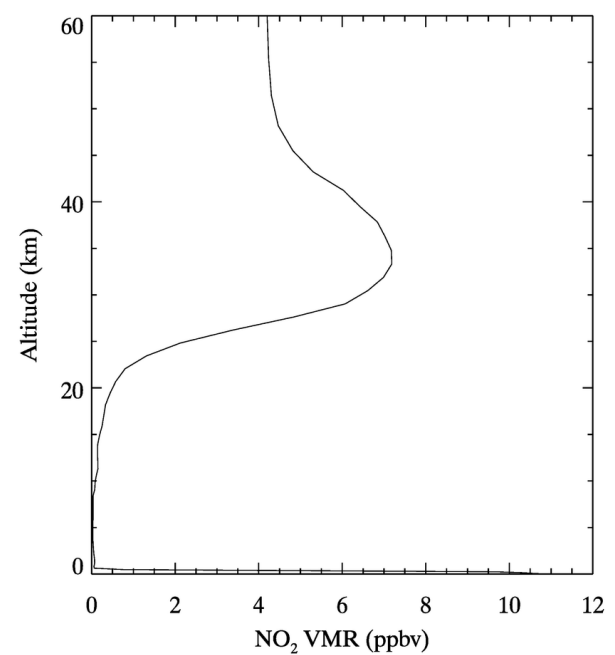

Figure 9. The mean MACC-II NO 2 profile forecast over Leicester at 12:00 (GMT) on 28 February 2013. The boundary layer profiles assumed in this work are shown in Fig. 17.

Table 3. The aerosol loading scenario based on the WMO climatology assumed for all ground pixels in this study.

\begin{tabular}{ll}
\hline Layer height $(\mathrm{km})$ & Mixing state \\
\hline $0.0-0.7$ & urban \\
$0.7-20.0$ & continental \\
$20.0-50.0$ & background \\
$50.0-100.0$ & background
\end{tabular}

ios the aerosol extinction profile was modelled as constant up to the boundary layer height and then exponentially decaying with height afterward (scale height: $0.2 \mathrm{~km}$ ). This profile was scaled to the mean aerosol optical depth (AOD) at $469 \mathrm{~nm}$ of 0.0798 forecasted over Leicester at the time of the flight by MACC-II.

In the absence of clouds and significant changes in the $\mathrm{NO}_{2}$ vertical profile surface albedo uncertainty can be a considerable source of error in the tropospheric $\mathrm{NO}_{2} \mathrm{AMF}$ computation (Boersma et al., 2004). This uncertainty can be greatly exacerbated by the use of surface albedo data sampled from data sets that are coarser than the instrument resolution (Heckel et al., 2011). In the case of the APEX flight campaign (Popp et al., 2012) this was acknowledged and avoided by directly calculating the surface albedo from the measured radiances which resulted in the surface albedo having the same spatial resolution as the retrieved $\mathrm{NO}_{2}$. For this work that approach could not be directly repeated, as the CompAQS spectrometer was not radiometrically calibrated pre-flight. Therefore instead the raw intensities from the CompAQS CCD were used to infer albedo with an empirical adjustment applied to them. The first component of the adjustment was to compensate for the effect of aerosols on the measured surface reflectance, which was partially re- 
moved through the use of an empirical correction factor for each ground pixel. The correction factor was calculated by first computing the expected intensity at $442.7 \mathrm{~nm}$ based on all forward model parameters using SCIATRAN for each ground pixel for scenarios with and without aerosol loading. The ratio of the two modelled intensities is then multiplied by the raw intensity measurement to generate an intensity data set with reduced aerosol influence.

Following the aerosol correction, the surface albedo of each ground pixel was approximated by linearly scaling the corrected surface intensities recorded by the spectrometer at a single wavelength $(442.7 \mathrm{~nm})$ between two reference albedo values. The intensities recorded over regions with water (albedo: 0.07; Clark et al., 2007) and white roofs (albedo: 0.56; Baldridge et al., 2009) were used as the references. For this method to be valid it is assumed that the sensitivity of the CompAQS CCD across the fitting window is correctly represented by $442.7 \mathrm{~nm}$. In the absence of characterisation data for the CompAQS CCD the accuracy of this approximation cannot be determined; however, a visual inspection of the intensity data across the fitting window did not reveal any significant sensitivity bias which would suggest the approximation is inappropriate.

A gridded data set of the AMFs computed for this work is shown in Fig. 10. The variability present in the data set is dominated by surface albedo, with bright surfaces (e.g. white roofs) coinciding with high AMFs and darker regions (e.g. parks, a canal/river) coinciding with lower AMFs. This is consistent with previous investigations (e.g. Boersma et al., 2004), in which the AMF is also shown to be most sensitive to surface albedo in the absence of clouds and significant variations in the $\mathrm{NO}_{2}$ profile.

\subsection{Vertical column density computation}

To calculate VCDs from the ANDI dSCD measurements it is necessary to account for tropospheric and stratospheric $\mathrm{NO}_{2}$ present in the DOAS reference region. The diurnal increase in stratospheric columnar $\mathrm{NO}_{2}$ has been previously estimated to be approximately $1.0 \times 10^{14} \mathrm{molec} \mathrm{cm}^{-2} \mathrm{~h}^{-1}$ (Sussmann et al., 2005), which is negligible in comparison to the VCDs retrieved which were on average approximately $3.5 \times 10^{16}$ molec $\mathrm{cm}^{-2}$. Therefore, it may be assumed that the stratospheric vertical column over the flight region remained approximately constant.

In a similar experiment involving imaging $\mathrm{NO}_{2}$ from aircraft, Popp et al. (2012) attempted to correct for reference region tropospheric $\mathrm{NO}_{2}$ in the retrieved dSCDs by adding a single offset estimated from previous air quality model studies (Huijnen et al., 2010). For the spatial scales covered in this work, however, this approach is unsuitable owing to the coarse spatial resolution offered by such models in comparison to the small region analysed. Instead, the dSCDs measured by ANDI are treated as the $\mathrm{NO}_{2}$ increment above the lowest dSCD measured throughout the flight, implying the

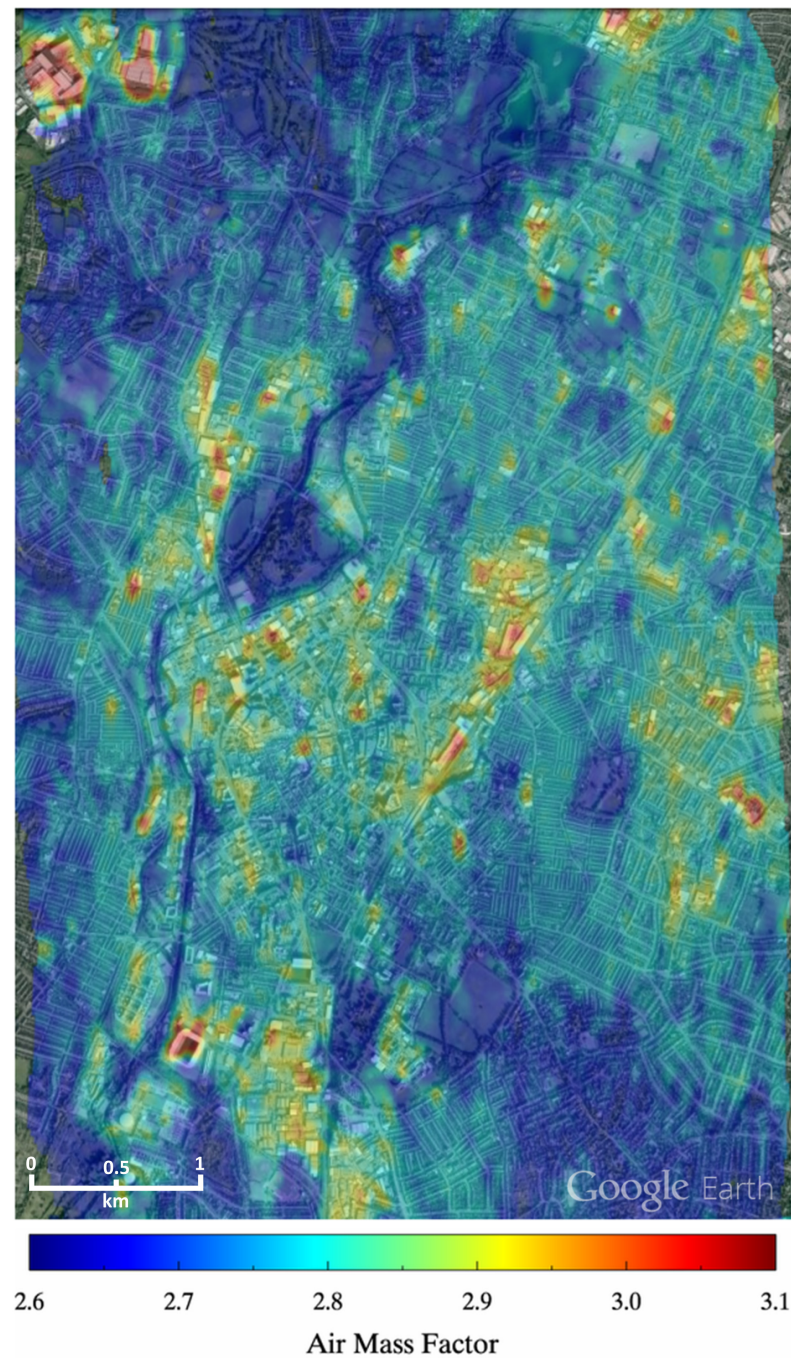

Figure 10. The gridded AMFs calculated for this work, overlaid on Google Earth, showing the sensitivity of the AMF computation to surface albedo. Bright regions such as white roofs result in higher AMFs, while darker regions such as rivers, canals and parkland have lower AMFs.

VCDs calculated from the flight are defined as the increment above UK background levels on the afternoon of the 28 February 2013.

\section{Results}

The test flight was divided into four components: three spatial regions, Leicester City centre, the M1 motorway and Ratcliffe-on-Soar power station, and a study on the temporal variability of $\mathrm{NO}_{2}$ over Leicester City centre. The findings from each of these components are covered separately in the following sections.

At the time of the flight, in situ measurements of $\mathrm{NO}_{2}$ were limited to hourly measurements from a single urban back- 


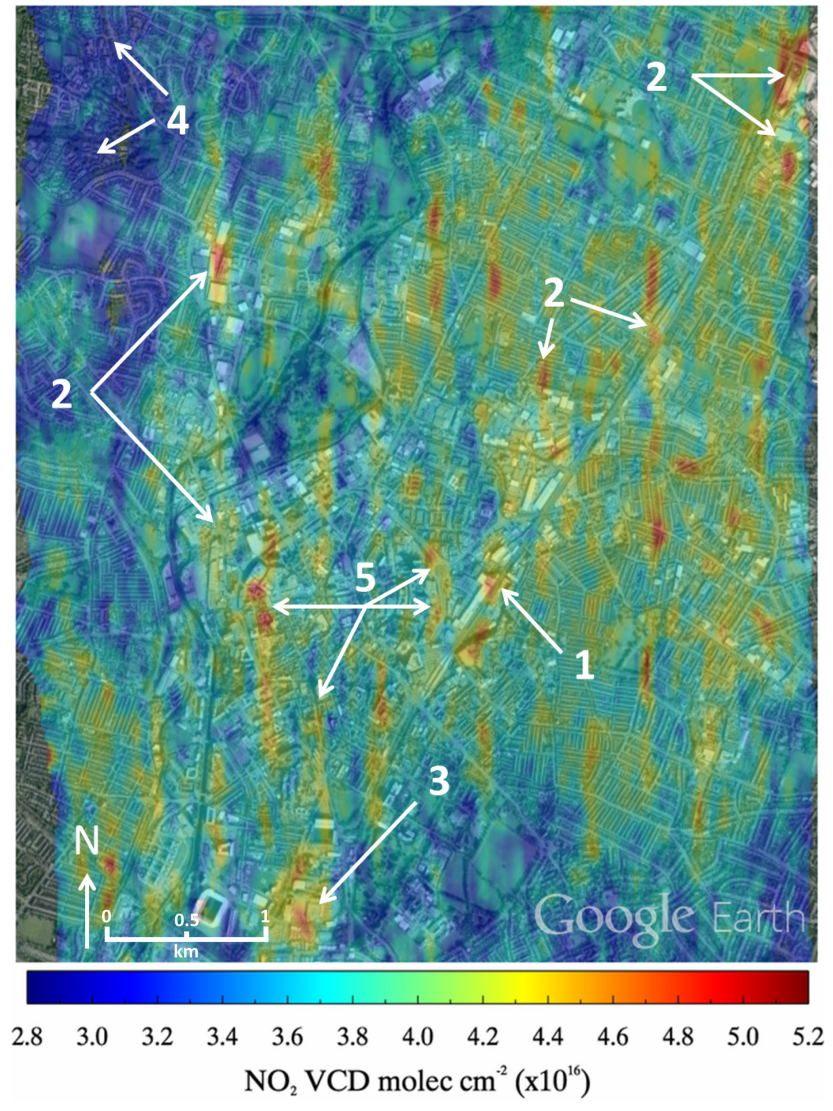

Figure 11. $\mathrm{NO}_{2}$ VCD data recorded over Leicester City centre overlaid on Google Earth with areas of interest highlighted. Regions of interest labelled in the diagram are the train station (1), industrial areas (2), car parks (3), farmland (4) and highly emitting roads and junctions (5).

ground site. Therefore, independent verification of the ANDI data was not possible in this work. Instead, relative comparisons between the regions were made to show that ANDI can retrieve the spatio-temporal variations in $\mathrm{NO}_{2}$ over the region.

However, the VCDs in this work are themselves relative to the background rural $\mathrm{NO}_{2}$ present at the reference region when the reference spectra were measured. The degree of this offset cannot be accurately estimated at the time of this work, but analysis of satellite-derived tropospheric $\mathrm{NO}_{2}$ VCDs from the Ozone Monitoring Instrument (OMI; Levelt et al., 2006) over Leicester measured during February 2013 suggest that the background column could be between 0.1 and $0.8 \times 10^{16}$ molec $^{-2}$. The presence of this unknown offset will have an impact on the relative differences calculated herein, so it is assumed that the background offset is the same over all regions, such that the VCDs measured in this work are the "urban enhancement" due to local emissions.

\subsection{Leicester City centre}

The main component of the ANDI test flight consisted of a series of 13 transects flown over Leicester City centre between 12:43 and 13:43 (GMT). From the ANDI data a map of $\mathrm{NO}_{2}$ VCDs was generated as shown in Fig. 11.

The VCDs recorded over Leicester City centre were measured to be on average $\sim 4.0 \times 10^{16} \mathrm{molec} \mathrm{cm}^{-2}$, approximately $0.65 \times 10^{16}$ molec $\mathrm{cm}^{-2}(20 \%)$ higher than in two of the city's suburban areas (see Fig. 13 and Table 5 for where these areas are defined). Contributing factors for this enhancement are road traffic and a number of discrete emission sources within and around the city centre, including high VCDs around the train station (1), industry (2), heavily used car parks such as supermarket and cinema car parks (3) and some particularly highly emitting roads and junctions (5) (see Fig. 11). The $\mathrm{NO}_{2} \mathrm{VCD}$ hotspots observed by ANDI were associated with various sources by identifying the land use directly beneath them. Any hotspots that were not easily associated with a particular source were not labelled in Fig. 11; however these sources are likely associated with road traffic as they are over areas where there are no obvious sources of industry or combustion activity.

Comparison of air masses in the city centre region (defined as region (c) in Fig. 13) with air masses which reside in the absence of busy roads and junctions such as over areas of vegetation and agriculture (4) provide an indication of the urban increment of atmospheric $\mathrm{NO}_{2}$ for Leicester City centre. An area of particularly low $\mathrm{NO}_{2} \mathrm{VCDs}$ is given as region (a) ii in Fig. 13 and Table 5 where there are very few roads and no sources of industrial activity. The city centre (region c) has a $1.04 \times 10^{16}$ molec $\mathrm{cm}^{-2}(36 \%)$ higher average VCD than region (a) ii; the majority of this increment is likely associated with Leicester's road traffic for reasons discussed.

A positive trend in atmospheric VCDs of $0.49 \times 10^{16}$ molec cm $^{-2} \mathrm{~h}^{-1}$ was measured over the city centre region from $12: 43$ to $13: 43$ (GMT), of which at least $0.23 \times 10^{16} \mathrm{molec}^{-2} \mathrm{~h}^{-1}$ has been identified as temporal in nature (see Sect. 4.4). Consequently the comparisons made between the city centre and other regions are only applicable to the time when the measurements were made. For the city centre (region c) the measurements were performed at approximately 13:10(GMT).

A striping feature present in the north-south direction in Fig. 11 is believed to be caused by along-track spatial interpolation and a shallow solar elevation angle (26 to $30^{\circ}$ ) during the flight resulting in artificially extended plumes (see Fig. 12). An additional enhancement is also present in the interpolated intensity data plotted in Fig. 5, affecting swaths where the aircraft was flying south towards the Sun's position at the time of the flight. One possible cause is that the enhanced diffuse radiance caused by the high solar zenith angle would cause a constant increase in measured intensity during north-to-south swaths. This effect could have been further 


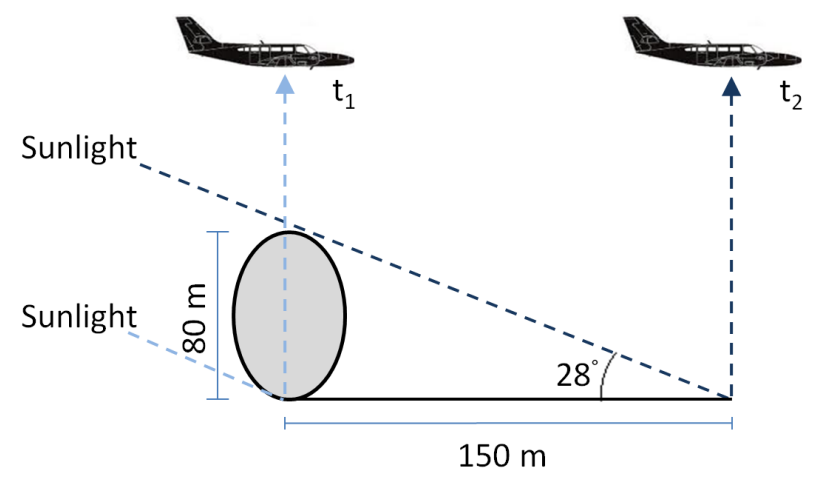

Figure 12. Schematic showing the contribution of solar geometry to the north-south striping seen in the data. Plumes $80 \mathrm{~m}$ high will produce $150 \mathrm{~m}$ artefacts on the surface. $t_{1}$ and $t_{2}$ correspond to two measurement intervals $150 \mathrm{~m}$ apart.

exaggerated by an additional pitch angle introduced by the ANDI instrument being misaligned on the aircraft so that it did not have an exactly nadir-centred viewing geometry.

The striping behaviour appears to be repeated in the AMF data in Fig. 10, though it does not appear as prevalent in the VCD data in Fig. 11. The albedo data were derived from the intensity data, so it is expected that the AMFs would exhibit similar behaviour. Figure 11 suggests that the albedo derivation has helped to at least partially account for this effect, but in future flights a functioning IMU would help to more precisely account for this effect.

The VCDs observed during the banking manoeuvres to the north-east of the city (see Fig. 13) at the end of each transect also show considerable enhancement, which does not correspond to known emission sources. The enhancement seen over that region is similar to those observed over the other banking manoeuvres during the flight, so it is possible that this is due to a large path length enhancement caused by a change in the roll angle. This would explain why the largest VCD appears to be at the outer edge of the swath, corresponding to the longest path length observed. As the IMU data were corrupted it was not possible to adequately include these effects in the AMF computation, which may lead to features such as this appearing in the final data set. It is likely that such features will not have appeared if the IMU was operational, and we envision that subsequent flights will not be subject to these effects.

\subsection{M1 motorway}

To investigate the contribution of the M1 motorway to local air quality the ANDI instrument was flown along a $24 \mathrm{~km}$ length of the M1 between 14:18 and 14:28 (GMT). Figure 13 highlights this component of the flight using two "M1" indicators. Towards the end of the M1 measurement region in the vicinity of Ratcliffe-on-Soar power station and East Midlands Airport (EMA), the VCDs became dominated by high
Table 4. VCD max, mean $(\bar{x})$ and standard deviations $(\sigma)$ in (molec $\left.\mathrm{cm}^{-2} \times 10^{16}\right)$ from selected areas within the ANDI gridded data (see Fig. 13). * Rural (a) $i$ is an anomaly discussed in Sect. 4.6. The times presented are the approximate measurement times for each region.

\begin{tabular}{lcccc}
\hline Region & Time & Max & $\bar{x}$ & $\sigma$ \\
\hline * Rural (a) i & $14: 15$ & 5.93 & 3.58 & 0.52 \\
Rural (a) ii & $12: 35$ & 4.73 & 2.92 & 0.48 \\
Suburbs (b) i & $13: 30$ & 5.14 & 3.19 & 0.49 \\
Suburbs (b) ii & $13: 05$ & 4.84 & 3.42 & 0.43 \\
City centre (c) & $13: 10$ & 6.06 & 3.96 & 0.45 \\
Power station (d) & $14: 25$ & 9.27 & 6.33 & 0.79 \\
\hline
\end{tabular}

concentrations (see Figs. 13 and 14). This region of high $\mathrm{NO}_{2}$ is likely associated with emissions from the power station and the airport. Before this area, however, there is no discernible $\mathrm{NO}_{2}$ signal originating from the motorway. This result may be due to low traffic volumes during the overpass as is indicated by the visible imagery captured during the flight, as well as good venting of the area owing to the exposed nature of the M1 motorway.

\subsection{Ratcliffe-on-Soar power station}

Ratcliffe-on-Soar power station is a $2000 \mathrm{MW}$ coal-fired power station $4.8 \mathrm{~km}$ from EMA, $9.7 \mathrm{~km}$ from Nottingham City centre and approximately $24 \mathrm{~km}$ from Leicester City centre. During the final few minutes of the test flight ANDI was flown directly over the power station to assess the magnitude and extent of its emissions. However, the spectrometer abruptly failed for $46 \mathrm{~s}$ during the overpass, which resulted in a gap in coverage. Figure 14 presents the ANDI VCD data for this area with an appropriate colour scale to identify structure in the $\mathrm{NO}_{2}$ concentrations near to the power station and EMA.

Table 4 summarises the average VCDs measured from six regions of interest (two rural regions, two suburban regions, the city centre and the power station) to put the $\mathrm{NO}_{2} \mathrm{VCDs}$ in these areas into context with the power station and each other.

As presented in Table 4, the VCD measurements taken in the area close to Ratcliffe-on-Soar power station and EMA (region (d) in Fig. 13) are approximately $2.37 \times 10^{16}$ molec $\mathrm{cm}^{-2}(60 \%)$ higher than the VCDs observed over Leicester City centre, approximately $3.03 \times 10^{16}$ molec $^{-2}(92 \%)$ higher than the VCDs observed over Leicester's suburbs and approximately $3.41 \times 10^{16}$ molec $\mathrm{cm}^{-2}(117 \%)$ higher than the VCDs observed over rural area (a) ii on average based on the regions sampled (see Fig. 13). The emissions from region (d) also appear to extend at least $16 \mathrm{~km}$ from their source, putting them in range of the town of Loughborough and the city of Nottingham. The flight did not cover the area sufficiently to de- 


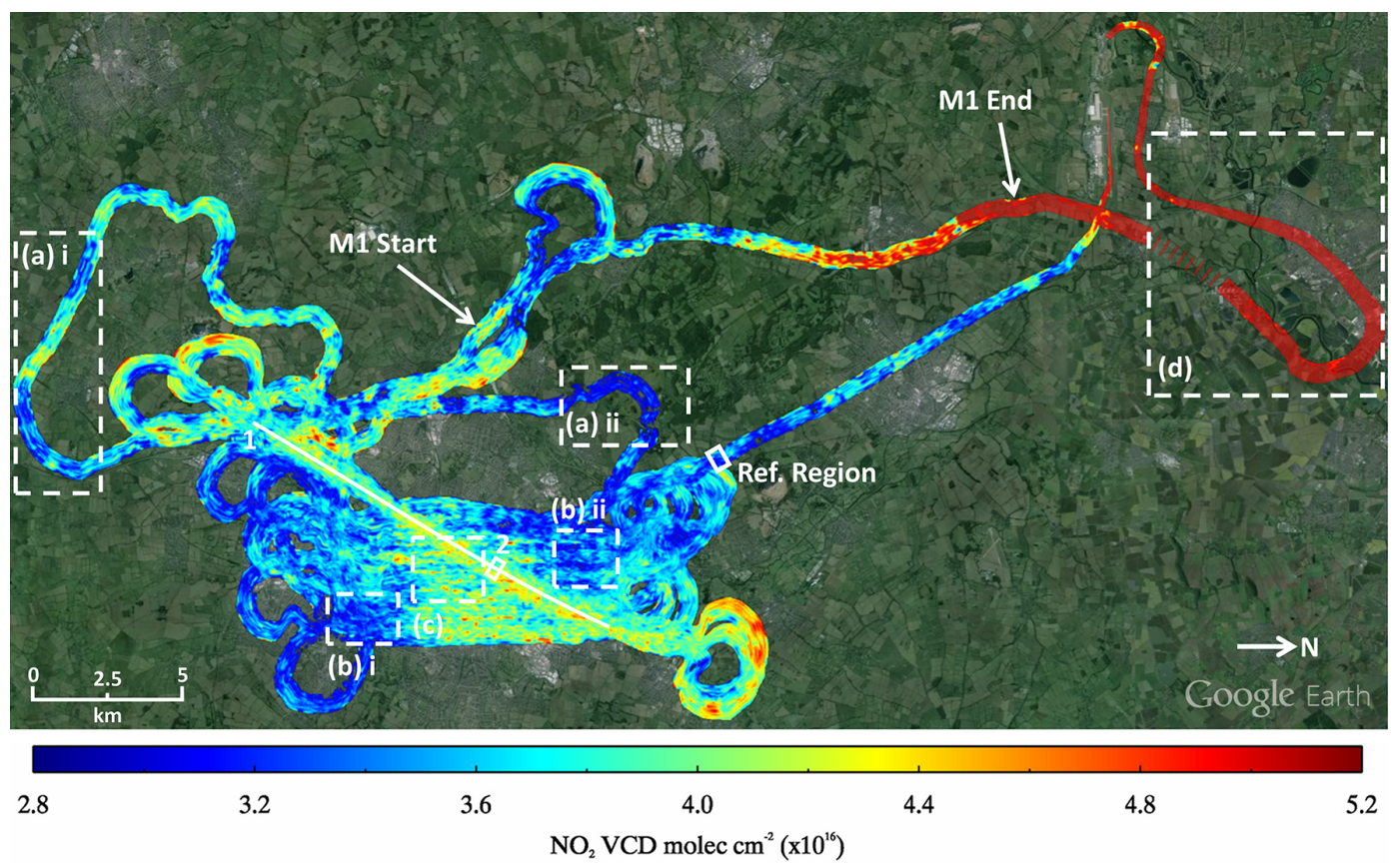

Figure 13. Complete ANDI data set from the test flight plotted in Google Earth with features of interest and areas used for regional averages highlighted. Coordinates for these regions are provided in Table 5. The gap in the data just prior to the power station is caused by the CompAQS spectrometer failing for $46 \mathrm{~s}$. The single scans downwind of the power station are from the instrument temporarily stopping and starting because of an issue with the control software.

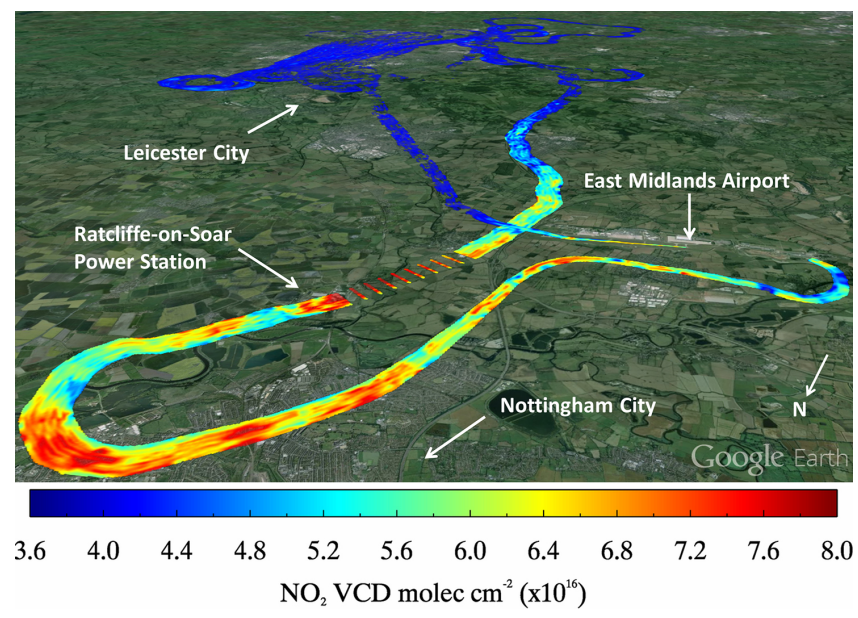

Figure 14. Google Earth overlay of $\mathrm{NO}_{2}$ VCDs over Leicester and an area close to Ratcliffe-on-Soar power station and EMA. The colour scale is appropriate to discern structure within the area. The emissions from the power station are likely elevated having been emitted from a $200 \mathrm{~m}$ high chimney. The gap in the data just prior to the power station is caused by the CompAQS spectrometer failing for $46 \mathrm{~s}$. The single scans downwind of the power station are from the instrument temporarily stopping and starting because of an issue with the control software.

termine the full extent of the plume or suitably identify the origin; therefore a future study may include a more exten- sive survey of this region and further consideration of how a plume aloft can be separated from surface concentrations.

It should be noted that the $\mathrm{NO}_{2}$ emitted from Ratcliffeon-Soar power station is released into the atmosphere from a $200 \mathrm{~m}$ high chimney stack. ANDI measures VCDs and therefore the vertical distribution of the power station emissions must be taken into account if surface concentrations are to be derived from these data. Additionally, the stack height influence was not accounted for in the static vertical profile used in the AMF computation, possibly further biasing the VCDs observed here.

Despite the difference in vertical profiles, the elevated VCDs observed over the power station show that ANDI is capable of resolving point emission sources above the local background.

\subsection{Temporal variability of $\mathrm{NO}_{2} \mathrm{VCDs}$}

To investigate the validity of characterising a city's $\mathrm{NO}_{2}$ distribution by measuring single instances of $\mathrm{NO}_{2} \mathrm{VCDs}$, a number of transects were flown along Narborough Road and the A6 (diagonally across the city centre) to observe the temporal variability of the $\mathrm{NO}_{2}$ VCDs. The GPS navigation system used by the pilot did not enable precise returns along the same course, however, restricting this part of the study to being largely qualitative. Figure 15 presents the $\mathrm{NO}_{2}$ data for four transects flown between approximately 13:40 and 14:00 (GMT). 


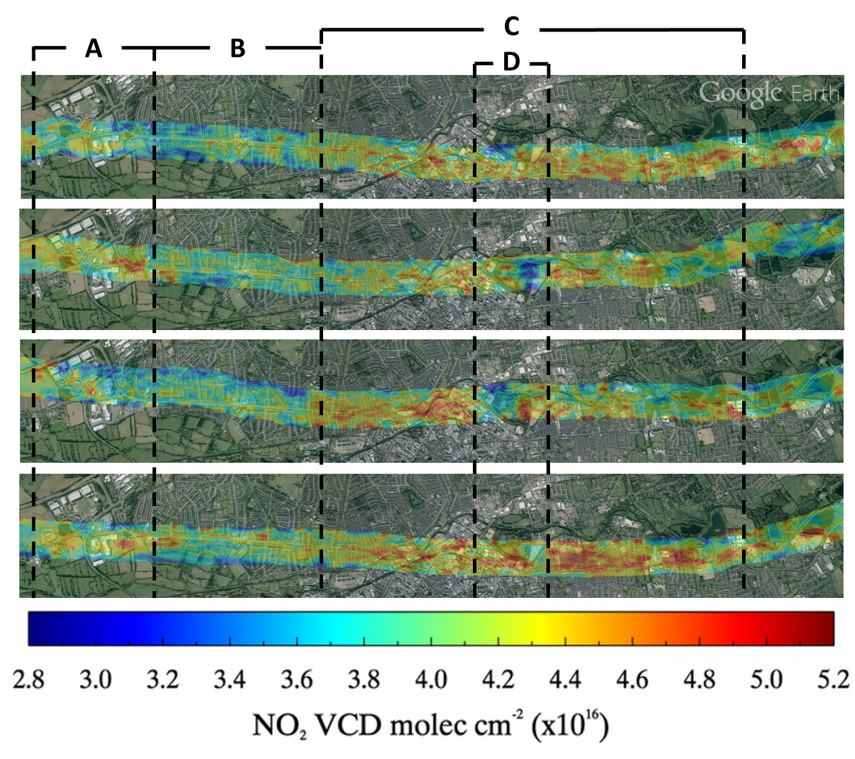

Figure 15. Google Earth overlay of the repeat $\mathrm{NO}_{2}$ measurements over Narborough road and the A6 moving through time from top to bottom. Each point on adjacent transects is approximately $6 \mathrm{~min}$ apart. Coordinates for the region are provided as region 1 in Table 5.

\subsection{Regional summary}

The results demonstrate both a temporal and spatial consistency in $\mathrm{NO}_{2} \mathrm{VCDs}$ throughout the 20 min the measurements were taken. On the left side of the transects (region A of Fig. 15) there is a temporally consistent area of relatively high $\mathrm{NO}_{2}$ VCDs which coincides with industrial buildings and a major road junction leading onto the M1 motorway. Between this junction and Leicester City centre (region B) there is a temporally consistent area of relatively low $\mathrm{NO}_{2}$ VCDs over an area of Leicester's suburbs. Towards the middle of each transect (region $\mathrm{C}$ ) there is a relatively high area of $\mathrm{NO}_{2}$ VCDs which is Leicester City centre, with a small but highly discrete area of relatively very low $\mathrm{NO}_{2} \mathrm{VCDs}$ near to the middle (region $\mathrm{D}$ ). The area of relatively low $\mathrm{NO}_{2}$ VCDs in the city centre is present in all four transects (though less obviously in the first and last transects); however its exact position and magnitude varies, which may be associated with a combination of meteorological and emission variability and to some degree georeferencing error on account of aircraft banking uncertainty, GPS precision and measurement location variability on account of ANDI's $80 \mathrm{~m}$ forward spatial resolution. The surface type beneath region $\mathrm{D}$ is parkland (Abbey Park), demonstrating the presence of a stable air mass with relatively few emissions beneath it.

From these qualitative observations it may be concluded that single instances of $\mathrm{NO}_{2} \mathrm{VCD}$ measurements are suitable for characterising the approximate spatial distribution and relative magnitude of a city's atmospheric $\mathrm{NO}_{2}$ concentrations on a regional urban scale $(>1 \mathrm{~km})$. However, the tempo-
Table 5. Coordinates for regions of interest the top 6 region identifiers are associated with Fig. 13, region 1 identifier with Fig. 15 and region 2 identifier with Table 6. (a) Rural areas, (b) suburban areas, (c) city centre area, (d) power station area.

\begin{tabular}{lcccc}
\hline Region & Long. low & Long. high & Lat. low & Lat. high \\
\hline (a) $\mathrm{i}$ & -1.292 & -1.168 & 52.508 & 52.535 \\
(a) ii & -1.226 & -1.186 & 52.672 & 52.706 \\
(b) $\mathrm{i}$ & -1.117 & -1.092 & 52.606 & 52.627 \\
(b) ii & -1.146 & -1.123 & 52.663 & 52.682 \\
(c) & -1.146 & -1.120 & 52.630 & 52.648 \\
(d) & -1.337 & -1.204 & 52.846 & 52.914 \\
1 & -1.134 & -1.132 & 52.645 & 52.646 \\
2 & -1.161 & -1.158 & 52.617 & 52.620 \\
\hline
\end{tabular}

ral and spatial variability observed for Abbey Park (region D) demonstrates that significant over- or underestimation of atmospheric concentrations of $\mathrm{NO}_{2}$ could occur at finer spatial scales $(<1 \mathrm{~km})$ if an individual measurement is attributed to average conditions, particularly where there are strong and potentially intermittent sources. This is also a reminder that these measurements are total column in nature and do not inform on the surface concentrations directly.

In addition to short-scale temporal variability presented in Fig. 15, a larger-scale temporal variability must also be considered if $\mathrm{NO}_{2}$ VCDs derived from ANDI (or a similar instrument) are to be used to characterise regional urban emissions. Throughout the $60 \mathrm{~min}$ that ANDI was flown over Leicester City centre (12:43 to $13: 43 \mathrm{GMT}$ ) the $\mathrm{NO}_{2}$ VCD measurements consistently increased. Linear regression analysis on the ANDI data (taking the average of the middle $60 \mathrm{CCD}$ pixels from CompAQS) revealed a statistically significant ( $p$ value $<0.001$ ) gradient of $0.49 \times 10^{16}$ molec cm $\mathrm{cm}^{-2} \mathrm{~h}^{-1}$ with a Pearson coefficient of 0.37 (see Fig. 16). The possibility that this result may be caused by an increase in aerosol loading which could artificially result in an observed increase in $\mathrm{NO}_{2} \mathrm{VCDs}$ is dismissed by analysis of $\mathrm{O}_{4}$ measurements obtained from CompAQS during the flight. Linear regression analysis on the $\mathrm{O}_{4}$ data indicated a statistically significant $6.4 \%$ temporal gradient in the atmospheric $\mathrm{O}_{4}$ absorption throughout the 12:43 to 13:43 (GMT) time period; however, this increase is explained by solar elevation variability which is expected to cause a $5.8 \%$ increase in atmospheric path length as indicated by SCIATRAN RTM simulations (using an urban atmospheric composition defined in Sect. 3.5). Since at first consideration an increase in $\mathrm{NO}_{2}$ between 12:43 and 13:43 (GMT) seems unlikely, an investigation was carried out to confirm this finding. Local meteorological data from Campbell Scientific (outside the city at lat. 52.7814 ${ }^{\circ}$, long. $-1.2844^{\circ}$ ) showed no particular trend during the flight aside from an increase in relative humidity $(\mathrm{RH})$ of approximately $12 \%$ from the start of the flight $(44 \%)$ to its end $(56 \%)$. During the time period shown in Fig. 17, the RH increased by approximately $8 \%$. To get a theoretical sense of 


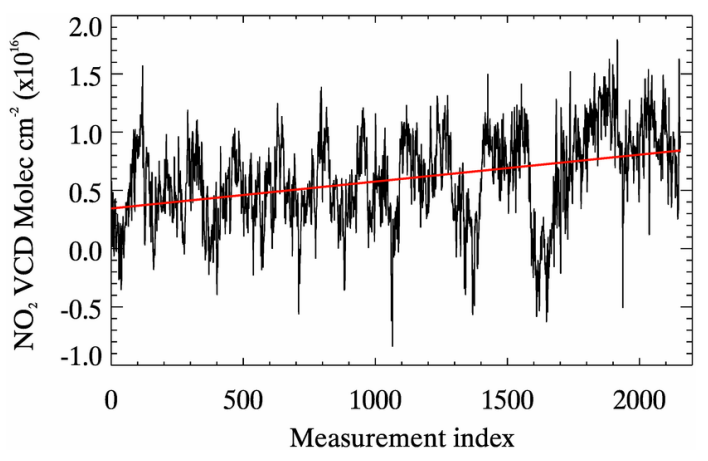

Figure 16. VCD measurements as a function of measurement index (time) with line of best fit presented in red. Measurements were averaged over \pm 30 pixels from the nadir, taken from 12:43 to 13:43. Line gradient is $0.49 \times 10^{16}$ molec $\mathrm{cm}^{2} \mathrm{~h}^{-1}$

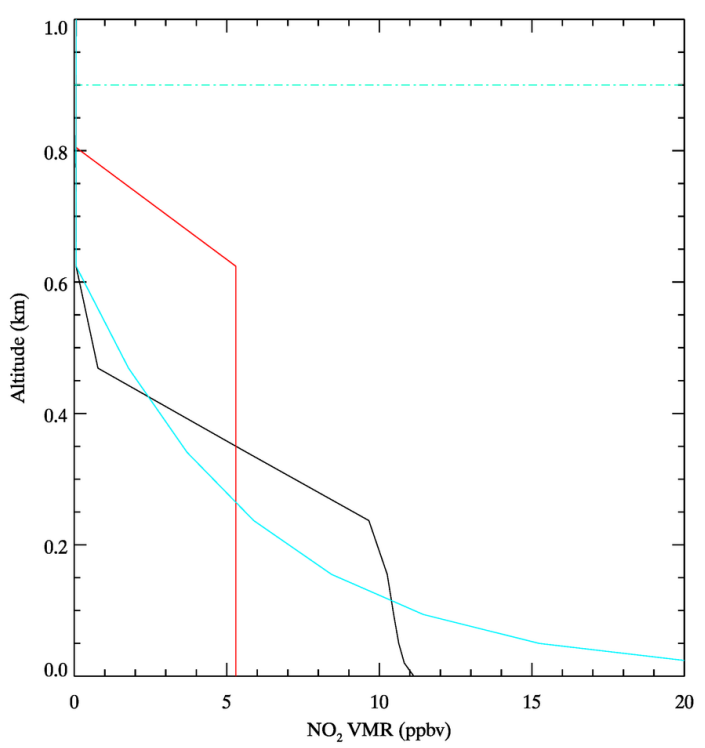

Figure 17. The constant (red) and exponential (blue) boundary layer $\mathrm{NO}_{2}$ profiles used in the perturbation study. Above $2 \mathrm{~km}$ the profile is the same as Fig. 9 (black). The dashed line represents the average flight altitude $(900 \mathrm{~m})$.

how this change might impact the AOD and in turn the AMF, the OPAC aerosol model (Hess et al., 1998) was used to estimate the impact with a continental average aerosol configuration. The results showed that an increase in $\mathrm{RH}$ from $50 \%$ to $60 \%$ would lead to an $8 \%$ increase in AOD at $450 \mathrm{~nm}$. However, as is shown in the perturbation study in Sect. 4.7.4, a $20 \%$ increase in AOD was calculated to change the retrieved $\mathrm{NO}_{2} \mathrm{VCD}$ by less than $1 \%$. Therefore, given the information available, the $6.4 \%$ increase in $\mathrm{NO}_{2}$ during this portion of the flight appears to be associated with an increase in atmospheric $\mathrm{NO}_{2}$, possibly as a result of emissions build-up in the atmosphere owing to slow wind speeds during the flight $\left(1.2 \mathrm{~m} \mathrm{~s}^{-1}\right.$ on average) combined with oxidation chemistry of $\mathrm{NO}$ to $\mathrm{NO}_{2}$.
Table 6. Average VCD measurements in molec $\mathrm{cm}^{-2} \times 10^{16}$ for region 2 in Table 5 for five overpasses.

\begin{tabular}{cc}
\hline Measurement time & $\mathrm{NO}_{2} \mathrm{VCD}$ \\
\hline $12: 40$ & 3.75 \\
$13: 43$ & 3.94 \\
$13: 49$ & 4.01 \\
$13: 54$ & 3.94 \\
$14: 01$ & 4.11 \\
\hline
\end{tabular}

To separate the temporal from the spatial (east to west) contributions within the observed VCD gradient, a region of interest (defined as 2 in Table 5) was averaged for five time intervals where spatial coincidence was achieved throughout the flight, thus obtaining $\mathrm{NO}_{2}$ measurements without significant spatial variability. The results are presented in Table 6 . The first data point of the five available was measured during the first overpass of region (c) in Fig. 13, which was $1 \mathrm{~h}$ prior to the following four data points which were taken during the repeated flights across Narborough Road and the A6.

The temporal gradient in the VCD measurements from the five data points is approximately $0.23 \times 10^{16} \mathrm{molec}^{2} \mathrm{~h}^{-1}$, confirming the existence of a temporal increase in $\mathrm{NO}_{2}$ concentrations throughout the flight. The difference in magnitude between this result and the temporal trend over the city centre $\left(0.49 \times 10^{16}\right.$ molec $\left.\mathrm{cm}^{2} \mathrm{~h}^{-1}\right)$ may be partially explained by the location of the region sampled, which was suburban and therefore will have lower $\mathrm{NO}_{2}$ emissions than the city centre. In addition it must be considered that the data used for the latter study were very sparse both temporally (only five data points) and spatially (only $220 \mathrm{~m} \times 220 \mathrm{~m}$ area) and therefore subject to significant uncertainty on account of local spatial and temporal variability in atmospheric composition and emission sources (see Fig. 15) as well as statistical error. In addition, the ANDI surface pixel locations differ from scene to scene within the region of interest which could also have led to differences in the results.

With recognition of the significant uncertainties involved in quantifying and characterising the VCD trend over the city centre, it may be concluded that at least $0.23 \times 10^{16}$ molec $\mathrm{cm}^{2} \mathrm{~h}^{-1}$ (47\%) of the $\mathrm{NO}_{2}$ trend is the result of a temporal increase in the atmospheric concentration of $\mathrm{NO}_{2}$ over the city centre.

\subsection{Spatial distribution of $\mathrm{NO}_{2} \mathrm{VCDs}$}

The ANDI test flight lasted $2 \mathrm{~h}$ and covered three distinctly different regions of Leicestershire (see Sect. 4). When plotted as a continuous data set, the ANDI results produce an extensive map of atmospheric $\mathrm{NO}_{2} \mathrm{VCDs}$ covering multiple land use types (see Fig. 13). Within the full ANDI data set two separate spatial scales of interest are present: the larger scale $(>1 \mathrm{~km})$ was captured in the regional comparison study included in Sect. 4.3 and presented in Table 4, in which the 
Table 7. Perturbation study results showing absolute and relative mean uncertainties $( \pm \delta \bar{x})$, maximum uncertainties ( $\pm \delta$ max) and standard deviations $( \pm \delta \sigma)$ for five perturbation scenarios. The $\mathrm{NO}_{2}$ profile shape study involves two alternative profile shapes (see Fig. 17); the results for each are presented in the + perturbation cells only. The units of the absolute uncertainties are in molec $\mathrm{cm}^{-2}$.

\begin{tabular}{llrrrrrr}
\hline Parameter & Perturbation & $+\delta \bar{x} \times 10^{13}$ & $-\delta \bar{x} \times 10^{13}$ & $+\delta \max \times 10^{14}$ & $-\delta \max \times 10^{14}$ & $+\delta \sigma \times 10^{13}$ & $-\delta \sigma \times 10^{13}$ \\
\hline Albedo & \pm 0.02 & $-14.1(-2.4 \%)$ & $18.3(2.8 \%)$ & $-17.6(-6.6 \%)$ & $9.7(1.4 \%)$ & $11.3(0.57 \%)$ & $11.9(0.21 \%)$ \\
$\mathrm{AOD}$ & $\pm 20 \%$ & $6.23(0.90 \%)$ & $-5.8(-0.82 \%)$ & $9.06(3.05 \%)$ & $-8.8(-2.51 \%)$ & $8.51(0.22 \%)$ & $8.29(0.27 \%)$ \\
$\mathrm{DEM}$ & $\pm 10 \mathrm{~m}$ & $-1.5(0.26 \%)$ & $-1.91(-0.34 \%)$ & $3.89(2.29 \%)$ & $-3.13(-0.72 \%)$ & $2.12(0.12 \%)$ & $2.57(0.14 \%)$ \\
$\mathrm{NO}_{2}$ Profile & exponential & $-13.4(-1.9 \%)$ & $\mathrm{n} / \mathrm{a}$ & $-17.2(-3.64 \%)$ & $\mathrm{n} / \mathrm{a}$ & $18.7(0.48 \%)$ & $\mathrm{n} / \mathrm{a}$ \\
$\mathrm{NO}_{2}$ Profile & well mixed & $-41.7(-6.5 \%)$ & $\mathrm{n} / \mathrm{a}$ & $-49.8(-8.22 \%)$ & $\mathrm{n} / \mathrm{a}$ & $59.6(1.7 \%)$ & $\mathrm{n} / \mathrm{a}$ \\
\hline
\end{tabular}

accumulation of multiple emission sources over time associated with a particular region appear to contribute to spatially extensive regional biases in atmospheric $\mathrm{NO}_{2}$ concentrations. The finer-scale variability $(<1 \mathrm{~km})$ is present in both Figs. 11 and 15, in which individual sources likely in combination with local meteorology appear to influence the local magnitude and distribution of the atmospheric $\mathrm{NO}_{2}$ concentrations. In the context of human exposure, consideration of both scales is important, as the large-scale variability demonstrated by the temporal trend discovered over the city centre (see Fig. 16) will modulate the finer-scale distributions which are of interest where concentrations may exceed legislated safe limits.

Repeat flights along Narborough Road discussed in Sect. 4.4 demonstrated the presence of a temporal component to the $\mathrm{NO}_{2} \mathrm{VCD}$ trend observed over the city centre; however, a contribution from an east-west spatial trend cannot be discounted.

Along-track spatial biases introduced by the low solar elevation angle and along-track spatial interpolation were potentially contributing factors to the partial disappearance of the area of low $\mathrm{NO}_{2}$ VCDs in the vicinity of Abbey Park in the top and bottom transects of Fig. 15. In addition, wind is likely to have also contributed to the differences observed in the transects, particularly over the Abbey Park area which may have been subject to import of $\mathrm{NO}_{2}$ from the surrounding road network. The wind speed measured by the Leicester City Council meteorological station (lat. $52.652^{\circ}$, long. $-1.176^{\circ}$ ) was approximately $1.2 \mathrm{~m} \mathrm{~s}^{-1}$ at $15^{\circ}$ from north, which varied by $<0.2 \mathrm{~m} \mathrm{~s}^{-1}$ and $5^{\circ}$ from north during the flight. The contribution of the wind vector to the spatial distribution of atmospheric $\mathrm{NO}_{2}$ is difficult to discern in the data sets owing to the spatial artefacts discussed previously and the low wind speed.

Region (a) $\mathrm{i}$ in Table 5 and Fig. 13 highlights an anomalous region of high $\mathrm{NO}_{2} \mathrm{VCDs}$ which is difficult to attribute to a particular source. The surface beneath region (a) $\mathrm{i}$ is farmland with only a single source of industry in the form of a small farm machinery factory and no additional sources of industry or major roads within a $1.6 \mathrm{~km}$ radius of the area. Despite the apparent scarcity of sources, the measured VCDs over this area are of a similar magnitude to Leicester City centre.

\subsection{Uncertainty analysis}

The error in the retrieved VCD measurements is a combination of the uncertainties in both the ASCD and AMF calculations.

The mean dSCD error across the flight can be calculated from the DOAS fit process. The mean dSCD over the flight was $1.9 \times 10^{16} \mathrm{molec}^{-2}$, while the mean error calculated from the DOAS fit was $7.0 \times 10^{15} \mathrm{molec} \mathrm{cm}^{-2}(37 \%)$.

The uncertainty in the AMF computation is more difficult to determine. An approximation for the uncertainty of some of the independent parameters associated with the AMF have been derived by means of a perturbation analysis. The results of the perturbation analysis are discussed for each parameter herein, with Table 7 presenting a summary of the uncertainties derived from the study.

\subsubsection{Methodology}

The uncertainties associated with the forward model parameters used to produce the AMFs are more difficult to quantify, as each parameter contributes to the overall error budget and in many cases the individual errors are unknown. To provide a simplified estimate for the retrieval uncertainty associated with the AMF computation, a perturbation analysis was performed and is presented in this section. It is assumed the independent parameters for the AMF are uncorrelated (i.e. their effects are independent of each other). Each forward model parameter in turn was perturbed by an error estimate resulting in perturbed AMF and VCD values for all ground pixels. The resulting VCDs were subsequently compared against the original VCDs, and the resulting difference was calculated based on the mean deviation from the original values over the entire flight. The VCD modulations caused by the perturbations are representative of a constant bias in the perturbed parameter throughout the flight and therefore provide an estimate for the relative importance of each independent parameter. The details of the parameters perturbed are discussed herein.

The DEM data set used in the AMF computation did not account for buildings, introducing a level of uncertainty to the VCDs measured over urban terrain owing to atmospheric path length uncertainties. To determine an approximation for 
the magnitude of the uncertainty associated with this omission, the DEM height used for each ground pixel was perturbed by $\pm 10 \mathrm{~m}$, which is approximately the mean building height in Leicester.

According to the MACC-II validation report for February 2013 (Eskes et al., 2013) the modelled AOD at $469 \mathrm{~nm}$ over England had an average bias of $-20 \%$ when compared with AERONET data. The AOD was therefore perturbed by $\pm 20 \%$ for this study. Additional sources of potential error associated with aerosols not accounted for in this study were the vertical profile of the aerosols and their single scattering albedo. It has been found that these factors can influence the sensitivity of the retrieval to $\mathrm{NO}_{2}$ below or within such aerosol layers (Leitão et al., 2010). For this work, no measurements that would yield information on such factors other than the boundary layer height were available, and therefore error estimates of these properties could not be reliably defined.

A previous study has shown that uncertainties in the $\mathrm{NO}_{2}$ profile shape can lead to AMF uncertainties of approximately $10 \%$ (Boersma et al., 2004). It is assumed in this work that the stratospheric $\mathrm{NO}_{2}$ concentration is approximately constant throughout the flight; therefore the $\mathrm{NO}_{2}$ profile uncertainty may be considered to be entirely associated with the correctness of the boundary layer $\mathrm{NO}_{2}$ profile component only. To obtain an approximation for the influence of boundary layer $\mathrm{NO}_{2}$ profile shape uncertainty on the VCD results, the MACC-II profile was altered to form two scenarios which would make sensible assumptions for the profile shape in the absence of additional information. The first scenario assumes the $\mathrm{NO}_{2}$ in the boundary layer (i.e. $<0.7 \mathrm{~km}$ ) is well mixed, and the second assumes the $\mathrm{NO}_{2}$ in the boundary layer decays exponentially with height. In both scenarios the net amount of $\mathrm{NO}_{2}$ in the boundary layer remained the same, ensuring that only the profile shape influenced the AMF. The modified profiles are shown in Fig. 17.

To estimate the uncertainty in the surface albedo a reference surface type was chosen to provide a metric against which to compare the ANDI albedo results. The reference surface for this study was chosen to be asphalt as it can be easily distinguished in the ANDI albedo data along the M1 motorway, reducing the risk of georeferencing error. The data for the study were taken during a parallel flight along the M1 such that the $80 \mathrm{~m} \times 5 \mathrm{~m}$ pixels of the ANDI system lay entirely over the motorway and not the surrounding countryside. Using albedos modelled in the ASTER data set for different road surface types (Baldridge et al., 2009) and estimates for the effect of aging on the albedo (Levinson and Akbari, 2002; Puttonen et al., 2009), the asphalt albedo was determined to be approximately 0.12 for $440 \mathrm{~nm}$ with an uncertainty of approximately 0.02 . The surface albedo derived from the spectral intensities over asphalt-covered pixels were 0.1235 on average, with a standard deviation of approximately 0.0015 . The ANDI measured values differ from the reference value by approximately $3 \%$ on average. Accom- modating the significant uncertainty in the reference used for the albedo results in an estimated error of approximately 0.02 , which is equivalent to an uncertainty of approximately $20 \%$ relative to the asphalt albedo in the albedo estimate for the RTM calculations.

A summary of the perturbations applied to each parameter and the results from the perturbation study are given in Table 7 and detailed in Sect. 4.7.2.

\subsubsection{Discussion}

The findings from the investigation demonstrate the dominant sources of uncertainty for the AMF computation are the $\mathrm{NO}_{2}$ profile shape in the boundary layer followed by the albedo uncertainty, with AOD and DEM errors being less important.

Assuming the four parameters investigated for the AMF uncertainty are the most relevant of the associated error sources, and that they may be treated as uncorrelated and random in nature, then an overall error estimate for the AMFs may be approximated by combining the square of the errors for each AMF parameter. The total AMF contribution to the error using this method is calculated to be approximately $3.25 \times 10^{14}$ molec cm $^{-2}$, which is $\sim 8 \%$ when applied to the flight data. Owing to the omission of some error contributors (see Sect. 4.7) and the nature of how this error estimate was derived, the quoted AMF contribution to the VCD error can only be considered to have an order of magnitude level of confidence.

\subsubsection{Albedo error}

The determination of absolute radiances from the recorded spectra would have led to an empirically derived albedo with comparatively little uncertainty (Popp et al., 2012); however the ANDI spectrometer was not radiometrically calibrated prior to the flight and therefore absolute radiances could not be computed from the measured intensities on the detector (see Sect. 4.7 for details). For the perturbation analysis, positive and negative perturbations respectively were applied with an uncertainty of 0.02 on the albedo estimates, and this resulted in an average of $-1.41 \times 10^{14}$ molec cm $^{-2}$ $(-2.4 \%)$ and $1.8 \times 10^{14}$ molec $\mathrm{cm}^{-2}(2.8 \%)$ errors in the VCD measurements (see Table 7).

\subsubsection{Aerosol optical depth}

The magnitude of the aerosol optical depth is a critical parameter used in the RTM for the AMF computation as it defines vertical sensitivity to $\mathrm{NO}_{2}$ and atmospheric path length, both of which significantly influence the magnitude of the AMF (see Sect. 4.7). For positive and negative perturbations respectively the estimated uncertainty of $\pm 20 \%$ on the AOD resulted in an average of $5.89 \times 10^{13} \mathrm{molec} \mathrm{cm}^{-2}(0.90 \%)$ and $-5.45 \times 10^{13}$ molec cm $^{-2}(-0.82 \%)$ errors in the VCD measurements (see Table 7). 


\subsubsection{DEM error}

The omission of building topography in the DEM data is likely to result in uncertainties in the AMF computation on account of incorrect atmospheric path length assumptions in the RTM (see Sect. 4.7). For positive and negative perturbations respectively the estimated uncertainty of $\pm 10 \mathrm{~m}$ in the DEM resulted in an average of $1.91 \times 10^{13} \mathrm{molec} \mathrm{cm}^{-2}$ $(0.34 \%)$ and $-1.5 \times 10^{13}$ molec $\mathrm{cm}^{-2}(-0.26 \%)$ errors in the VCD measurements (see Table 7).

\subsubsection{Profile shape}

As part of the AMF computation the RTM requires an assumed $\mathrm{NO}_{2}$ profile shape to determine vertical sensitivity. The shape of the $\mathrm{NO}_{2}$ profile was unknown at the time of the measurements; therefore a simulated profile from the MACC II ensemble product was used for all retrievals. To provide perturbation on the profile shape, two alternative profiles were formed (see Sect. 4.7); their affect on the AMF calculation is presented in Table 7. The use of a well-mixed profile as opposed to the MACC II profile in the RTM simulations resulted in a substantial modulation of the VCD results of $-41.7 \times 10^{13}(-6.5 \%)$. The use of an exponential profile as opposed to the MACC II profile generated a less significant modulation of approximately $-13.4 \times 10^{13}(-1.9 \%)$.

\section{Conclusions}

The results in this paper demonstrate that the ANDI instrument can provide a unique and informative perspective on atmospheric $\mathrm{NO}_{2}$ distributions around an urban environment.

The measurements identified elevated $\mathrm{NO}_{2}$ concentrations in the proximity of Ratcliffe-on-Soar power station and East Midlands Airport which were approximately $60 \%$ higher than the concentrations present over Leicester City centre and extended over $16 \mathrm{~km}$ from their source. The emissions from the city centre appear to be largely from traffic, with some instances of emissions originating from discrete industrial sources and the train line. However, it should be noted that without full knowledge of the rural background concentration at the time of the reference measurement such comparisons are relative to an unknown background column. The comparisons in this work were made under the assumption that there was no significant difference in background $\mathrm{NO}_{2}$ between observations. Future flights will need to be supported by independent measurements or modelled estimations of the local $\mathrm{NO}_{2}$ field during the reference spectra measurement.

A temporal increase in $\mathrm{NO}_{2}$ concentrations in the atmosphere above Leicester City was observed, leading to a regional bias becoming larger throughout the day. Quantifying the temporal gradient from the ANDI measurements was difficult owing to a lack of data for separating the spatial from the temporal contributions. In situ measurements in a $1 \mathrm{~km}$ grid around the city would be recommended in future to aid in separating the spatial and temporal variability in the data.

Multiple spatial and temporal scales were observed in the $\mathrm{NO}_{2}$ distributions throughout the flight varying from tens of metres and minutes to kilometres and hours. The variety of scales at which $\mathrm{NO}_{2}$ can be seen to change suggests care must be taken if using an instrument such as ANDI to characterise $\mathrm{NO}_{2}$ in an urban atmosphere. There is a need to accommodate both temporal and spatial variability when drawing conclusions on both small-scale and regional-scale $(\mathrm{km})$ concentrations. Owing to a lack of in situ measurements at the time of the flight it is difficult to verify this variability. Future flights will therefore be supported by a network of in situ sensors to compare against these measurements.

During the flight along the M1 motorway there was no measured enhancement in $\mathrm{NO}_{2}$ concentrations; however, analysis of visible imagery suggests at the time of the flight the M1 was resident to very little traffic.

The ANDI viewing geometry is dependent on the solar elevation angle which contributed to a north-south striping in the data owing to the flight occurring in February. A reduction in the influence of solar geometry on the retrievals could be achieved if the instrument were flown at noon during the summer months. Additional along-track striping occurred through the use of forward interpolation; achieving faster read-out speeds on the spectrometer would reduce this dependency.

The primary uncertainty in the VCD measurements was the DOAS fit which had a $37 \%$ error. This uncertainty primarily arises from the signal-to-noise ratio (SNR) of the instrument, which could potentially be improved by increasing the CCD binning. However, the coarser spatial resolution caused by this binning may make the features discussed in this work more difficult to ascertain. Future revisions of the ANDI design will consider this trade-off between spatial resolution and SNR.

The AMF uncertainty was difficult to ascertain with confidence, a value of approximately $8 \%$ was derived based on the information available. The majority of the AMF error is attributed to potential uncertainties in the $\mathrm{NO}_{2}$ profile shape and the surface albedo. The latter contribution will be addressed in future flights through pre-flight radiometric calibration of the spectrometer, as will the uncertainty in the SCD measurements through improved optical alignment of the spectrometer.

Acknowledgements. This work was funded by the Centre for Earth Observation and Instrumentation CEOI (contract number 4500153612) in partnership with BlueSky International Ltd. Additional funding was provided through NERC grant no. NE/L002930/1. The CompAQS spectrometer was also funded by a number of separate grants through the CEOI. Consultation on aircraft installation was given by RVL-Group, and meteorological and ceilometer backscatter data were provided by Campbell Scientific Ltd. This research used the ALICE High Performance 
Computing Facility at the University of Leicester.

Edited by: U. Platt

\section{References}

Aliwell, S. R., Van Roozendael, M., Johnston, P. V., Richter, A., Wagner, T., Arlander, D. W., Burrows, J. P., Fish, D. J., Jones, R. L., Tørnkvist, K. K., Lambert, J.-C., Pfeilsticker, K., and Pundt, I.: Analysis for BrO in zenith-sky spectra: An intercomparison exercise for analysis improvement, J. Geophys. Res.Atmos., 107, 10-1-10-20, doi:10.1029/2001JD000329, 2002.

Baldridge, A. M., Hook, S. J., Grove, C. I., and Rivera, G.: The ASTER spectral library version 2.0, Remote Sens. Environ., 113, 711-715, doi:10.1016/j.rse.2008.11.007, 2009.

Boersma, K. F., Eskes, H. J., and Brinksma, E. J.: Error analysis for tropospheric $\mathrm{NO}_{2}$ retrieval from space, J. Geophys. Res., 109, D04311, doi:10.1029/2003JD003962, 2004.

Bogumil, K., Orphal, J., Homann, T., Voigt, S., Spietz, P., Fleischmann, O., Vogel, A., Hartmann, M., Kromminga, H., Bovensmann, H., Frerick, J., and Burrows, J.: Measurements of molecular absorption spectra with the SCIAMACHY pre-flight model: instrument characterization and reference data for atmospheric remote-sensing in the $230-2380 \mathrm{~nm}$ region, J. Photoch. Photobio. A, 157, 167-184, doi:10.1016/S1010-6030(03)00062-5, 2003.

Bolle, H. J.: A preliminary cloudless standard atmosphere for radiation computation, Tech. rep., World Meteorological Organization, Geneva, Switzerland, 1986.

Bucsela, E. J., Perring, A. E., Cohen, R. C., Boersma, K. F., Celarier, E. A., Gleason, J. F., Wenig, M. O., Bertram, T. H., Wooldridge, P. J., Dirksen, R., and Veefkind, J. P.: Comparison of tropospheric $\mathrm{NO}_{2}$ from in situ aircraft measurements with near-real-time and standard product data from OMI, J. Geophys. Res.-Atmos., 113, D16S31, doi:10.1029/2007JD008838, 2008.

Carslaw, D. C., Beevers, S. D., Tate, J. E., Westmoreland, E. J., and Williams, M. L.: Recent evidence concerning higher $\mathrm{NO}_{x}$ emissions from passenger cars and light duty vehicles, Atmos. Environ., 45, 7053-7063, doi:10.1016/j.atmosenv.2011.09.063, 2011.

CERC: Validation and sensitivity study of ADMS-Urban for London, Tech. rep., CERC, http://www.cerc.co. uk/environmental-research/assets/data/CERC_2003_

ADMS-Urban_validation_and_sensivity_study_for_London_ 10_TR-0191-h.pdf (last access: 1 April 2015), 2003.

Chance, K. V. and Spurr, R. J. D.: Ring effect studies: Rayleigh scattering, including molecular parameters for rotational Raman scattering, and the Fraunhofer spectrum, Appl. Opt., 36, 52245230, doi:10.1364/AO.36.005224, 1997.

Clark, R., Swayze, G., Wise, R., Livo, E., Hoefen, T., Kokaly, R., and Sutley, S.: USGS digital spectral library splib06a: U.S. Geological Survey, Digital Data Series 231, Tech. rep., U.S. Geological Survey, http://speclab.cr.usgs.gov/spectral.lib06/ (last access: 1 April 2015), 2007.

COMEAP: Review of the UK Air Quality Index, A report by the Committee on the Medical Effects of Air Pollutant, Tech. rep., COMEAP, https://www.gov.uk/government/ collections/comeap-reports/ (last access: 1 April 2015), 2011.

Davies, E.: Leicester City's Air Quality Action Plan 20112016, Tech. rep., LCC, www.leicester.gov.uk/media/178152/ air-quality-action-plan-2011-2016.pdf (last access: 1 April 2015), 2011.

de Haij, M., Wauben, W., Klein Baltink, H., and Apituley, A.: Determination of the mixing layer height by a ceilometer, in: Proceedings of the 8th International Symposium on Tropospheric Profiling, 18-23 October 2009, Delft, the Netherlands, 2009.

EEA: Revealing the costs of air pollution from industrial facilities in Europe, Tech. rep., EEA, http://www.eea.europa.eu/publications/ cost-of-air-pollution/ (last access: 1 April 2015), 2011.

Eskes, H., Huijnen, V., Wagner, A., Schulz, M., and Lefever, K.: Validation report of the MACC nearreal time global atmospheric composition service. System evolution and performance statistics Status up to February 2013, Tech. rep., MACC Technical report, D_82.8, http://www.copernicus-atmosphere.eu/ documents/maccii/delivera\%bles/val/MACCII_VAL_DEL_D_ 82.8_NRTReport06_20130621.pdf (last access: 1 April 2015), 2013.

Fayt, C., De Smedt, I., Letocart, V., Merlaud, A., Pinardi, G., and Van Roozendael, M.: QDOAS Software user manual, BIRA-IASB, http://uv-vis.aeronomie.be/software/QDOAS/ index.php, last access: 1 April 2015.

General, S., Pöhler, D., Sihler, H., Bobrowski, N., Frieß, U., Zielcke, J., Horbanski, M., Shepson, P. B., Stirm, B. H., Simpson, W. R., Weber, K., Fischer, C., and Platt, U.: The Heidelberg Airborne Imaging DOAS Instrument (HAIDI) - a novel imaging DOAS device for 2-D and 3-D imaging of trace gases and aerosols, Atmos. Meas. Tech., 7, 3459-3485, doi:10.5194/amt7-3459-2014, 2014.

Greenblatt, G. D., Orlando, J. J., Burkholder, J. B., and Ravishankara, A. R.: Absorption measurements of oxygen between 330 and $1140 \mathrm{~nm}$, J. Geophys. Res.-Atmos., 95, 18577-18582, doi:10.1029/JD095iD11p18577, 1990.

Heckel, A., Kim, S.-W., Frost, G. J., Richter, A., Trainer, M., and Burrows, J. P.: Influence of low spatial resolution a priori data on tropospheric $\mathrm{NO}_{2}$ satellite retrievals, Atmos. Meas. Tech., 4, 1805-1820, doi:10.5194/amtd-7-3591-2014, 2011.

Hess, M., Koepke, P., and Schult, I.: Optical properties of aerosols and clouds: The software package OPAC, B. Am. Meteorol. Soc., 79, 831-844, 1998.

Heue, K.-P., Wagner, T., Broccardo, S. P., Walter, D., Piketh, S. J., Ross, K. E., Beirle, S., and Platt, U.: Direct observation of two dimensional trace gas distributions with an airborne Imaging DOAS instrument, Atmos. Chem. Phys., 8, 6707-6717, doi:10.5194/acp-8-6707-2008, 2008.

Hilboll, A., Richter, A., Rozanov, A., Hodnebrog, Ø., Heckel, A., Solberg, S., Stordal, F., and Burrows, J. P.: Improvements to the retrieval of tropospheric $\mathrm{NO}_{2}$ from satellite - stratospheric correction using SCIAMACHY limb/nadir matching and comparison to Oslo CTM2 simulations, Atmos. Meas. Tech., 6, 565-584, doi:10.5194/amt-6-565-2013, 2013.

HoCEAC: Air quality: A follow up report, ninth report of Session 2010-12, Tech. rep., HoCEAC, http: //www.publications.parliament.uk/pa/cm201012/cmselect/ cmenvaud/1024/1024.pdf (last access: 1 April 2015), 2011.

Huijnen, V., Eskes, H. J., Poupkou, A., Elbern, H., Boersma, K. F., Foret, G., Sofiev, M., Valdebenito, A., Flemming, J., Stein, O., Gross, A., Robertson, L., D'Isidoro, M., Kioutsioukis, I., Friese, E., Amstrup, B., Bergstrom, R., Strunk, A., Vira, J., Zyryanov, D., Maurizi, A., Melas, D., Peuch, V.-H., and Zerefos, C.: Com- 
parison of $\mathrm{OMI} \mathrm{NO}_{2}$ tropospheric columns with an ensemble of global and European regional air quality models, Atmos. Chem. Phys., 10, 3273-3296, doi:10.5194/acp-10-3273-2010, 2010.

Kramer, J. L., Leigh, R. J., Remedios, J. J., and Monks, P.: Comparison of OMI and ground-based in situ and MAX-DOAS measurements of tropospheric nitrogen dioxide in an urban area, J. Geophys. Res., 113, D16S39, doi:10.1029/2007JD009168, 2008.

Kurucz, R. L., Furenlid, I., Brault, J., and Testerman, L.: Solar flux atlas from 296 to $1300 \mathrm{~nm}$, National Solar Observatory Atlas, US. National Solar Observatory, Sunspot, New Mexico, USA, 1984.

Latza, U., Gerdes, S., and Baur, X.: Effects of nitrogen dioxide on human health: Systematic review of experimental and epidemiological studies conducted between 2002 and 2006, Int. J. Hyg. Envir. Heal., 212, 271-287, doi:10.1016/j.ijheh.2008.06. 003, 2008

Leigh, R. J., Leigh, R., Whyte, C., Lawrence, J. P., Abbey, A. F., Lobb, D., Cutter, M., and Monks, P. S.: Investigating spatial structure in above-rooftop urban $\mathrm{NO}_{2}$ using hemispherical scanning imaging DOAS, in preparation, 2015.

Leitão, J., Richter, A., Vrekoussis, M., Kokhanovsky, A., Zhang, Q. J., Beekmann, M., and Burrows, J. P.: On the improvement of $\mathrm{NO}_{2}$ satellite retrievals - aerosol impact on the airmass factors, Atmos. Meas. Tech., 475-493, doi:10.5194/amt-3-475-2010, 2010.

Levelt, P., van den Oord, G., Dobber, M., Malkki, A., Visser, H., de Vries, J., Stammes, P., Lundell, J., and Saari, H.: The ozone monitoring instrument, IEEE T. Geosci. Remote, 44, 1093-1101, doi:10.1109/TGRS.2006.872333, 2006

Levinson, R. and Akbari, H.: Effects of composition and exposure on the solar reflectance of portland cement concrete, Cement Concrete Res., 32, 1679-1698, doi:10.1016/S0008-8846(02) 00835-9, 2002.

Monks, P. S., Granier, C., Fuzzi, S., Stohl, A., Williams, M. L., Akimoto, H., Amann, M., Baklanov, A., Baltensperger, U., Bey, I., Blake, N., Blake, R. S., Carslaw, K., Cooper, O. R., Dentener, F., Fowler, D., Fragkou, E., Frost, G. J., Generoso, S., Ginoux, P., Grewe, V., Guenther, A., Hansson, H. C., Henne, S., Hjorth, J., Hofzumahaus, A., Huntrieser, H., Isaksen, I. S. A., Jenkin, M. E., Kaiser, J., Kanakidou, M., Klimont, Z., Kulmala, M., Laj, P., Lawrence, M. G., Lee, J. D., Liousse, C., Maione, M., McFiggans, G., Metzger, A., Mieville, A., Moussiopoulos, N., Orlando, J. J., O’Dowd, C. D., Palmer, P. I., Parrish, D. D., Petzold, A., Platt, U., Pöschl, U., Prévôt, A. S. H., Reeves, C. E., Reimann, S., Rudich, Y., Sellegri, K., Steinbrecher, R., Simpson, D., ten Brink, H., Theloke, J., van der Werf, G. R., Vautard, R., Vestreng, V., Vlachokostas, C., and von Glasow, R.: Atmospheric composition change - global and regional air quality, Atmos. Environ., 43, 5268-5350, doi:10.1016/j.atmosenv.2009.08.021, 2009.

Palmer, P. I., Jacob, D. J., Chance, K., Martin, R. V., Spurr, R. J. D., Kurosu, T. P., Bey, I., Yantosca, R., Fiore, A., and Li, Q. B.: Air mass factor formulation for spectroscopic measurements from satellites: Application to formaldehyde retrievals from the Global Ozone Monitoring Experiment, J. Geophys. Res., 106, 1453914550, 2001.

Platt, U. and Stutz, J.: Differential Absorption Spectroscopy, in: Differential Optical Absorption Spectroscopy, Physics of Earth and Space Environments, Springer, Berlin Heidelberg, Germany, 135-174, doi:10.1007/978-3-540-75776-4_6, 2008.
Popp, C., Brunner, D., Damm, A., Van Roozendael, M., Fayt, C., and Buchmann, B.: High-resolution $\mathrm{NO}_{2}$ remote sensing from the Airborne Prism EXperiment (APEX) imaging spectrometer, Atmos. Meas. Tech., 5, 2211-2225, doi:10.5194/amt-5-22112012, 2012.

Puttonen, E., Suomalainen, J., Hakala, T., and Peltoniemi, J.: Measurement of Reflectance Properties of Asphalt Surfaces and Their Usability as Reference Targets for Aerial Photos, IEEE T. Geosci. Remote, 47, 2330-2339, doi:10.1109/TGRS.2008. 2010132, 2009.

Rothman, L., Barbe, A., Benner, D. C., Brown, L., Camy-Peyret, C., Carleer, M., Chance, K., Clerbaux, C., Dana, V., Devi, V., Fayt, A., Flaud, J.-M., Gamache, R., Goldman, A., Jacquemart, D., Jucks, K., Lafferty, W., Mandin, J.-Y., Massie, S., Nemtchinov, V., Newnham, D., Perrin, A., Rinsland, C., Schroeder, J., Smith, K., Smith, M., Tang, K., Toth, R., Auwera, J. V., Varanasi, P., and Yoshino, K.: The HITRAN molecular spectroscopic database: edition of 2000 including updates through 2001, J Quant. Spectrosc. Ra., 82, 5-44, doi:10.1016/S0022-4073(03)00146-8, 2003.

Rozanov, A., Rozanov, V., Buchwitz, M., Kokhanovsky, A., and Burrows, J. P.: SCIATRAN 2.0 - A new radiative transfer model for geophysical applications in the $175-2400 \mathrm{~nm}$ spectral region, Adv. Space Res., 36, 1015-1019, doi:10.1016/j.asr.2005. 03.012, 2005.

Rozanov, V. V. and Rozanov, A. V.: Differential optical absorption spectroscopy (DOAS) and air mass factor concept for a multiply scattering vertically inhomogeneous medium: theoretical consideration, Atmos. Meas. Tech., 751-780, doi:10.5194/ amt-3-751-2010, 2010.

Schönhardt, A., Altube, P., Gerilowski, K., Krautwurst, S., Hartmann, J., Meier, A. C., Richter, A., and Burrows, J. P.: A wide field-of-view imaging DOAS instrument for continuous trace gas mapping from aircraft, Atmos. Meas. Tech. Discuss., 7, 35913644, doi:10.5194/amtd-7-3591-2014, 2014.

Solomon, S., Schmeltekopf, A. L., and Sanders, R. W.: On the interpretation of zenith sky absorption measurements, J. Geophys. Res., 92, 8311-8319, 1987.

Stein, O., Flemming, J., Inness, A., Kaiser, J. W., and Schultz, M. G.: Global reactive gases forecasts and reanalysis in the MACC project, Journal of Integrative Environmental Sciences, 9, 57-70, doi:10.1080/1943815X.2012.696545, 2012.

Sussmann, R., Stremme, W., Burrows, J. P., Richter, A., Seiler, W., and Rettinger, M.: Stratospheric and tropospheric NO2 variability on the diurnal and annual scale: a combined retrieval from ENVISAT/SCIAMACHY and solar FTIR at the Permanent Ground-Truthing Facility Zugspitze/Garmisch, Atmos. Chem. Phys., 5, 2657-2677, doi:10.5194/acp-5-2657-2005, 2005.

Vandaele, A., Hermans, C., Simon, P., Van Roozendael, M., Guilmot, J., Carleer, M., and Colin, R.: Fourier transform measurement of $\mathrm{NO}_{2}$ absorption cross-section in the visible range at room temperature, J. Atmos. Chem., 25, 289-305, doi:10.1007/BF00053797, 1996.

Vardoulakis, S., Valiantis, M., Milner, J., and ApSimon, H.: Operational air pollution modelling in the UK - Street canyon applications and challenges, Atmos. Environ., 41, 4622-4637, doi:10.1016/j.atmosenv.2007.03.039, 2007.

Volkamer, R., Spietz, P., Burrows, J., and Platt, U.: High-resolution absorption cross-section of Glyoxal in the UV/vis and IR spec- 
tral ranges, J. Photoch. Photobio. A, 172, 35-46, doi:10.1016/j. jphotochem.2004.11.011, 2005.

Wang, S., Zhou, B., Wang, Z., Yang, S., Hao, N., Valks, P., Trautmann, T., and Chen, L.: Remote sensing of $\mathrm{NO}_{2}$ emission from the central urban area of Shanghai (China) using the mobile DOAS technique, J. Geophys. Res.-Atmos., 117, D13305, doi:10.1029/2011JD016983, 2012.

Wehner, B. and Wiedensohler, A.: Long term measurements of submicrometer urban aerosols: statistical analysis for correlations with meteorological conditions and trace gases, Atmos. Chem. Phys., 3, 867-879, doi:10.5194/acp-3-867-2003, 2003.
Whyte, C., Leigh, R. J., Lobb, D., Williams, T., Remedios, J. J., Cutter, M., and Monks, P. S.: Assessment of the performance of a compact concentric spectrometer system for Atmospheric Differential Optical Absorption Spectroscopy, Atmos. Meas. Tech., 2, 789-800, doi:10.5194/amt-2-789-2009, 2009.

Zhou, Y., Brunner, D., Boersma, K. F., Dirksen, R., and Wang, P.: An improved tropospheric $\mathrm{NO}_{2}$ retrieval for OMI observations in the vicinity of mountainous terrain, Atmos. Meas. Tech., 2, 401-416, doi:10.5194/amt-2-401-2009, 2009. 